\title{
Klebsiella pneumoniae subsp. pneumoniae-bacteriophage combination from the caecal effluent of a healthy woman
}

Lesley Hoyles, James Murphy, Horst Neve, Knut J Heller, Jane F Turton, Jennifer Mahony, Jeremy D Sanderson, Barry Hudspith, Glenn R Gibson, Anne L McCartney, Douwe van Sinderen

A sample of caecal effluent was obtained from a female patient who had undergone a routine colonoscopic examination. Bacteria were isolated anaerobically from the sample, and screened against the remaining filtered caecal effluent in an attempt to isolate bacteriophages (phages). A lytic phage, named KLPN1, was isolated on a strain identified as Klebsiella pneumoniae subsp. pneumoniae (capsular type $\mathrm{K} 2, r m p A^{+}$). This Siphoviridae phage presents a rosette-like tail tip and exhibits depolymerase activity, as demonstrated by the formation of plaque-surrounding haloes that increased in size over the course of incubation. When screened against a panel of clinical isolates of $K$. pneumoniae subsp. pneumoniae, phage KLPN1 was shown to infect and lyse capsular type K2 strains, though it did not exhibit depolymerase activity on such hosts. The genome of KLPN1 was determined to be 49,037 bp $(50.53 \% G C)$ in length, encompassing 73 predicted ORFs, of which 23 represented genes associated with structure, host recognition, packaging, DNA replication and cell lysis. On the basis of sequence analyses, phages KLPN1 (GenBank: KR262148) and 1513 (a member of the family Siphoviridae, GenBank: KP658157) were found to be two new members of the genus "Kp36likevirus". 
2 Klebsiella pneumoniae subsp. pneumoniae-bacteriophage combination from the caecal

3 effluent of a healthy woman

4

5 Lesley Hoyles ${ }^{1,2 *}$, James Murphy ${ }^{1 *}$, Horst Neve ${ }^{3}$, Knut J. Heller ${ }^{3}$, Jane F. Turton ${ }^{4}$, Jennifer

6 Mahony $^{1}$, Jeremy D. Sanderson ${ }^{5}$, Barry Hudspith ${ }^{5}$, Glenn R. Gibson ${ }^{6}$, Anne L. McCartney ${ }^{6}$ and

7 Douwe van Sinderen ${ }^{1,7}$

$9 \quad{ }^{1}$ School of Microbiology, University College Cork, Cork, Ireland

$10{ }^{2}$ Department of Biomedical Sciences, University of Westminster, 115 New Cavendish Street,

11 London W1W 6UW, United Kingdom

$12{ }^{3}$ Max Rubner - Institut (MRI), Institute of Microbiology and Biotechnology (MBT), Kiel,

13 Germany

$14{ }^{4}$ Antimicrobial Resistance and Healthcare Associated Infections Reference Unit, Public Health

15 England - Colindale, 61 Colindale Avenue, London NW9 5EQ, United Kingdom

16 5Department of Gastroenterology, Guy's and St Thomas' NHS Foundation Trust and King's

17 College London, London, United Kingdom

$18{ }^{6}$ Food Microbial Sciences Unit, Department of Food and Nutritional Sciences, University of

19 Reading, Whiteknights Campus, Reading, Berkshire, United Kingdom

$20 \quad{ }^{7}$ Alimentary Pharmabiotic Centre, University College Cork, Cork, Ireland

22 Correspondence: Douwe van Sinderen, d.vansinderen@ucc.ie; Lesley Hoyles,

23 1.hoyles@westminster.ac.uk

$24 *$ These authors made equal contributions to this work. 
26 Keywords: depolymerase, biofilm, microbial ecology, gut microbiota, Siphoviridae

27 Abbreviations: ESBL, extended-spectrum $\beta$-lactamase; VLP, virus-like particle; VNTR, 28 variable number tandem repeat.

29

30 Running title: Lytic bacteriophage from human caecum 


\section{ABSTRACT}

A sample of caecal effluent was obtained from a female patient who had undergone a

34 routine colonoscopic examination. Bacteria were isolated anaerobically from the sample, and

35 screened against the remaining filtered caecal effluent in an attempt to isolate bacteriophages

36 (phages). A lytic phage, named KLPN1, was isolated on a strain identified as Klebsiella

37 pneumoniae subsp. pneumoniae (capsular type K2, rmp $A^{+}$). This Siphoviridae phage presents a

38 rosette-like tail tip and exhibits depolymerase activity, as demonstrated by the formation of

39 plaque-surrounding haloes that increased in size over the course of incubation. When screened

40 against a panel of clinical isolates of K. pneumoniae subsp. pneumoniae, phage KLPN1 was

41 shown to infect and lyse capsular type K2 strains, though it did not exhibit depolymerase activity

42 on such hosts. The genome of KLPN1 was determined to be $49,037 \mathrm{bp}(50.53 \% \mathrm{GC})$ in length,

43 encompassing 73 predicted ORFs, of which 23 represented genes associated with structure, host

44 recognition, packaging, DNA replication and cell lysis. On the basis of sequence analyses,

45 phages KLPN1 (GenBank: KR262148) and 1513 (a member of the family Siphoviridae,

46 GenBank: KP658157) were found to be two new members of the genus "Kp36likevirus". 


\section{INTRODUCTION}

Metagenomic studies on samples from a range of different environments and the potential of bacteriophage (phage) therapy to treat antibiotic-resistant, clinically relevant bacteria have renewed interest in virus-like particles (VLPs). Metagenomic (virome) studies, in particular, have demonstrated that VLPs are the most genetically diverse entities in the biosphere (Reyes et al., 2012). Given their staggering abundance and diversity, coupled to their perceived crucial role in the functioning of ecosystems, it is surprising that VLPs (and by extension, phages) remain the most poorly characterized biological entities (Reyes et al., 2012).

Virome and classical studies examining VLPs in the faeces of adults and infants have demonstrated that there is a vast diversity and abundance of phages associated with the human gut microbiota (Breitbart et al., 2003, 2008; Lepage et al., 2008; Reyes et al., 2010; Kim et al., 2011; Minot et al., 2011; Wagner et al., 2013; Hoyles et al., 2014). Similar to the prokaryotic make-up of the human gut microbiota, each individual harbours a unique virome (dsDNA, ssDNA, RNA) that is temporally stable, and whose composition appears to be influenced by diet (Reyes et al., 2010; Minot et al., 2011, 2013). Lepage et al. (2008) reported that mucosal biopsies taken from healthy individuals and Crohn's patients contained between $4.4 \times 10^{7}$ and $1.7 \times 10^{10}\left(\right.$ mean $\left.1.2 \times 10^{9}\right)$ VLPs/biopsy, with Crohn's patients harbouring significantly more VLPs in their biopsies than healthy individuals. A recent study in which phage populations in human faecal and caecal-effluent samples were estimated using epifluorescence microscopy (EFM) and transmission electron microscopy (TEM) reported the presence of up to $10^{12} \mathrm{VLPs} / \mathrm{g}$ faeces $(\mathrm{EFM})$ and at least $1 \times 10^{5} \mathrm{VLPs} / \mathrm{ml}$ caecal effluent (TEM) (Hoyles et al., 2014).

However, little is known about the host ranges of these VLPs, and their abundance within other regions of the gastrointestinal tract. 
Generation of comprehensive gut virome data has been hampered by the lack of available

73 methods for concentrating VLPs within faecal samples and extracting sufficient amounts of

74 DNA from them so sequencing can be performed without the need to amplify the template DNA

75 (Reyes et al., 2012). However, the recent publication of a PEGylation method applied to human

76 faecal samples and demonstration that microgram quantities of DNA can be isolated from faecal

77 VLPs has gone some way to overcome this substantial technical hurdle (Hoyles et al., 2014).

78 When it comes to annotation of virome sequence data, a major stumbling block is the lack of

79 available phage genome sequences against which contigs can be compared, plus the large

80 number of viral genes that are currently not represented in sequence databases. For example,

81 studies of the human faecal virome have reported that between $66 \%$ and $98 \%$ of the generated

82 sequences have no significant hits with GenBank sequences (Breitbart et al., 2008; Reyes et al.,

83 2010; Minot et al., 2011). There are few, if any, available sequences for human-gut-associated

84 lytic phages so there is a need to isolate and genomically characterize phages from

85 gastrointestinal sources, rather than relying on the assumption that phages found in sewage are

86 primarily of human gut origin. However, sequences of (predicted) prophages from genome

87 sequences of bifidobacteria, lactobacilli, Helicobacter pylori and Escherichia coli (strain Nissle

88 1917) of gastrointestinal origin are available (Ventura et al., 2005; Villion \& Moineau, 2009;

89 Vejborg et al., 2010; Luo et al., 2012).

90 During a study of the microbiota associated with the caecum of patients with Irritable

91 Bowel Syndrome and healthy controls, attempts were made to isolate bacterium-phage

92 combinations from samples of caecal effluent. Herein, we report the isolation and

93 characterization of a Klebsiella pneumoniae subsp. pneumoniae-phage combination from the

94 caecal effluent of a healthy woman, and the implications of our findings in relation to 
95

96

97

98

99

100

101 Jamal et al., 2015). was transported to the University of Reading under anaerobic conditions (in a gas jar with an anaerobic gas-generating pack; Oxoid Ltd) and on ice, where it was processed within $3 \mathrm{~h}$ of collection. The sample was transferred to an anaerobic cabinet (Whitley MG1000 anaerobic workstation, DW Scientific; gas composition $80 \% \mathrm{~N}_{2}, 10 \% \mathrm{H}_{2}, 10 \% \mathrm{CO}_{2}$ ) and mixed well by

117 shaking. An aliquot $(1 \mathrm{ml})$ of the sample was diluted with $9 \mathrm{ml}$ sterile, anaerobic half-strength 
118 peptone water (Oxoid) in a sterile universal bottle containing 2-mm glass beads. A dilution series

$119\left(10^{-1}\right.$ to $\left.10^{-6}\right)$ was prepared from the homogenate in sterile, anaerobic half-strength peptone water

120 (Oxoid). Aliquots $(20 \mu 1)$ were plated in triplicate onto fastidious anaerobic agar (BIOTEC

121 laboratories, Ipswich, UK) containing $5 \%$ laked horse blood. Bacteria were incubated

122 anaerobically for 5 days at $37^{\circ} \mathrm{C}$, and then enumerated. Ten colonies were selected randomly,

123 streaked to purity, and stored on Microbank cryogenic beads (Prolab Diagnostics) at $-70{ }^{\circ} \mathrm{C}$.

124 The remaining neat caecal effluent $(\sim 25 \mathrm{ml})$ was processed as described by Hoyles et al.

125 (2014). Briefly, the sample was diluted 1:4 (v/v) with sterile TBT buffer (100 mM Tris/HCl, pH

$1268.0 ; 100 \mathrm{mM} \mathrm{NaCl} ; 10 \mathrm{mM} \mathrm{MgCl}{ }_{2} \bullet 6 \mathrm{H}_{2} \mathrm{O}$ filtered through a $0.1 \mathrm{~mm}$ pore size filter prior to

127 autoclaving). The sample was homogenized in a stomacher (Stomacher 400 Lab System;

128 Seward) for $2 \mathrm{~min}$ at 'high' speed, and then placed on ice for $2 \mathrm{~h}$ to allow detachment of phages

129 from and settlement of particulate material. The homogenate was centrifuged at $11,180 \mathrm{~g}$ for 30

$130 \min$ at $4{ }^{\circ} \mathrm{C}$, and the supernatant passed through a sterile $0.45 \mu \mathrm{m}$ cellulose acetate filter

131 (Millipore). The filtrate was stored at $4{ }^{\circ} \mathrm{C}$ until used in spot assays.

132

133 Identification of isolated bacteria. DNA was isolated from bacteria using InstaGene Matrix

134 (Bio-Rad) according to the manufacturer's instructions. Partial ( 600 nt) 16S rRNA gene

135 sequences were obtained for the isolates via the University of Reading's Biocentre. Nearest

136 relatives of isolates were determined using EzTaxon (Chun et al., 2007). The identity of strain

137 L4-FAA5, tentatively identified as Klebsiella pneumoniae on the basis of its 16S rRNA gene

138 sequence, was confirmed using a species-specific PCR that detects the $16 \mathrm{~S}-23 \mathrm{~S}$ internal

139 transcribed spacer unit of $K$. pneumoniae as well as capsular-type-specific, and virulence gene

140 targets (Turton et al., 2010). Malonate and Voges-Proskauer reactions were positive indicating 
141 that the isolate was subsp. pneumoniae (rather than subsp. ozaenae) (Turton et al., 2010). Typing

142 was carried out by VNTR analysis at loci A, E, H, J, K and D (Turton et al., 2010) and an

143 additional three loci (N1, N2 and N4). Primers, repeat sizes and flanking sequence sizes for the

144 additional loci were: N1F 5'-CATCAGGTGCAAGATTCCA-3' and N1R 5'-

145 TGAGCGATTGCTGGCCTA-3', 116 bp repeat with a 107 bp flanking sequence; N2F 5'-

146 GATGCGGCAAGCACCAC-3' and N2R 5'-ACGCCCTGACCATTATGC-3', 57 bp repeat

147 with a 109 bp flanking sequence; and N4F 5'-GTGCGGTGATTGTGATGG-3' and N4R 5'-

148 CTGACAACGTCGATGTGG-3', 67 bp repeat with a 119 bp flanking sequence.

149

150 Screening of bacteria against filtered caecal effluent. K. pneumoniae strains isolated from the

151 caecum were grown to $\mathrm{OD}_{660} \sim 0.4$ in tryptone soya broth (Oxoid Ltd), and used in spot assays as

152 follows. An aliquot of culture (200 $\mu \mathrm{l})$ was inoculated into $3 \mathrm{ml}$ tryptone soya broth containing

$1530.3 \%(\mathrm{w} / \mathrm{v})$ agarose (SeaKem LE agarose; Lonza Rockland) that had been heat-treated by

154 microwaving and dispensed aseptically from a larger volume before cooling to $48^{\circ} \mathrm{C}$. The

155 overlays containing bacteria were poured over $20 \mathrm{ml}$ solid agar plates of autoclaved tryptone

156 soya agar (Oxoid Ltd). Once the agar had solidified, a $10 \mu \mathrm{l}$ spot of filtered caecal effluent was

157 applied to the overlays, and the plates were incubated overnight at $37^{\circ} \mathrm{C}$ in the anaerobic

158 cabinet. Identical plaques were observed on all K. pneumoniae isolates; strain L4-FAA5 was

159 used to propagate and purify an isolated phage in tryptone soya broth or reinforced clostridial

160 and nutrient media (Oxoid Ltd). Neither calcium nor magnesium was added to media during

161 propagations. 
163 clinical isolates (Table 1) was determined using the spot assay as described above, except that

164 nutrient agar plates were used for the base. Strain L4-FAA5 was used as a positive control.

166 Purification of phage particles. A 100-ml culture of strain L4-FAA5 was grown to mid-

167 exponential phase, inoculated with $100 \mu \mathrm{l}$ of phage stock $\left(\sim 10^{10} \mathrm{pfu} / \mathrm{ml}\right)$ and incubated until the 168 medium became clear ( $\sim 2 \mathrm{~h}$ after infection). The lysate was centrifuged at $4,500 \mathrm{~g}$ for $10 \mathrm{~min}$, 169 then passed through a $0.45 \mu \mathrm{m}$ cellulose acetate filter. PEG $8000(10 \%, \mathrm{w} / \mathrm{v})$ and $\mathrm{NaCl}(6 \%$, $170 \mathrm{w} / \mathrm{v})$ were added to the filtrate, and mixed until all particulates had dissolved. The sample was 171 left at $4{ }^{\circ} \mathrm{C}$ for $16 \mathrm{~h}$, then centrifuged at $4,500 \mathrm{~g}$ for $30 \mathrm{~min}$. The supernatant was removed and

172 the pellet resuspended in $4 \mathrm{ml}$ TBT buffer. A CsCl block gradient was formed with $5 \mathrm{M}$ and $3 \mathrm{M}$

$173 \mathrm{CsCl}$, both prepared in TBT buffer and samples were placed on top of this gradient and subjected 174 to centrifugation at $100,000 \mathrm{~g}$ for $2 \mathrm{~h}$ at $4{ }^{\circ} \mathrm{C}$. The band containing $\sim 2 \mathrm{ml}$ of TBT buffer and the 175 phages was drawn out of the tube and the purified sample was transferred to dialysis tubing 176 (4,000-6,000 Da cut-off), and dialysed against TBT buffer overnight. The TBT buffer was

177 replaced with fresh TBT buffer, and the sample dialysed for a further $4 \mathrm{~h}$. The purified phage

178 particles were removed from the dialysis tubing and stored at $4{ }^{\circ} \mathrm{C}$.

180 Transmission electron microscopy. This was done as described by Hoyles et al. (2014). 181

182 Extraction of DNA from phage KLPN1 and restriction enzyme profiles. An aliquot (250 $\mu 1)$

183 of the purified phage particle stock was treated with DNAse (2 U) for $30 \mathrm{~min}$ at $37^{\circ} \mathrm{C}$, then 184 heated for $10 \mathrm{~min}$ at $80^{\circ} \mathrm{C}$. Two phenol/chloroform extractions were performed, before the DNA 
185 was precipitated using $1 / 10$ volume of $3 \mathrm{M}$ sodium acetate $(\mathrm{pH} 4.8)$ and 2 volumes of ice-cold

186 ethanol. After air-drying, DNA was resuspended in $100 \mu 1 \mathrm{TE}$ buffer. Restriction profiles were

187 obtained for phage KLPN1 using the enzymes EcoRV and HaeIII (SuRE/Cut; Roche Applied

188 Science): restriction digests contained $3 \mu 1 \mathrm{H}_{2} \mathrm{O}, 1 \mu 1$ enzyme, $1 \mu 1$ enzyme buffer and $5 \mu 1$ DNA,

189 and were incubated for $3 \mathrm{~h}$ at $37^{\circ} \mathrm{C}$ before being run on a $0.8 \%(w / v)$ agarose gel $(1 \mathrm{~h}, 75 \mathrm{~V})$

190 and stained with ethidium bromide.

191

192 Whole-genome sequencing and annotation of the phage genome. DNA (5 $\mu \mathrm{g})$ was extracted

193 and concentration verified by Nanodrop quantification. Confirmatory molecular identification

194 tests were also conducted on the DNA extract prior to shipment to the contract sequencing

195 facility (Macrogen Inc., Korea). Eighty-fold sequencing coverage was obtained using

196 pyrosequencing technology on a 454 FLX instrument. The individual sequence files generated

197 by the 454 FLX instrument were assembled with GSassembler (454 Lifesciences, Branford, CT)

198 to generate a consensus sequence. To ensure correct assembly and resolve any remaining base-

199 conflicts, short segments of the genome were amplified by PCR and the generated amplicons

200 were then subjected to Sanger sequencing (MWG, Ebersberg, Germany). Open reading frames

201 (ORFs) were automatically predicted using Genemark (Besemer \& Borodovsky, 1999). General

202 feature format (gff) files were generated for the predicted phage proteome (retaining proteins

203 with a minimum size of 30 amino acids) and visualized using the annotation software Artemis

204 v10.0 (Rutherford et al., 2000). ORF boundaries were verified and, where required, adjusted by

205 manual inspection of Shine-Delgarno sequences. BLASTP (Altschul et al., 1990) was used to

206 provide preliminary functional annotation data, and to carry out a comparative analysis of

207 KLPN1 with previously sequenced Klebsiella phages at the protein level (Altschul et al., 1990). 
208 To improve genome annotations/predictions, all proteins encoded by ORFs in the genome 209 sequence of KLPN1 were searched against InterProScan (http://www.ebi.ac.uk/interpro/).

210 HHpred (http://toolkit.tuebingen.mpg.de/hhpred) searches were done to identify domains

211 associated with depolymerase activity.

212

213 Screening virome datasets for phage sequences related to KLPN1. Fasta files associated with

214 public virome datasets were downloaded from the METAVIR web server (http://metavir-

215 meb.univ-bpclermont.fr; Roux et al., 2011) on 31 March 2015 (Supplementary Table 1). Each

216 fasta file was used to create a BLAST database, against which the genome sequence of phage

217 KLPN1 was searched using BLASTN.

218

219

220

221

222

223

224

225

226

227

228

229

230

\section{RESULTS}

\section{Isolation and characterization of bacteria isolated from caecal effluent}

On fastidious anaerobe agar, $2.22 \times 10^{8} \pm 5.30 \times 10^{7}(n=3$ replica plating) bacteria were isolated per millilitre of caecal effluent sample ( $\log _{10} 8.35 \pm 7.72$ bacteria/ml caecal effluent). Ten colonies were randomly selected from one of the triplicate plates used to enumerate the bacteria, and streaked to purity. On the basis of 16S rRNA gene sequence analysis (EzTaxon), isolates represented Klebsiella pneumoniae ( $n=5)$, Bacteroides vulgatus $(n=2)$, Bacteroides massiliensis $(n=1)$, a novel member of the order Erysipelotrichales distantly related to [Clostridium] innocuum ( $n=1)$, and Haemophilus parainfluenzae $(n=1)$.

It is widely accepted that identification of members of the family Enterobacteriaceae is difficult on the basis of 16S rRNA gene sequence data alone; therefore, one of the strains 
231 identified as K. pneumoniae, L4-FAA5, was characterized using the PCR-based methods of

232 Turton et al. (2010). The isolate was found to be a strain of K. pneumoniae subsp. pneumoniae,

233 capsular type $\mathrm{K} 2, r m p A^{+}$. Its VNTR profile was unique among the clinical isolates tested and on

234 the wider database of clinical isolates held by Public Health England - Colindale.

235

\section{Screening of filter-sterilized caecal effluent against bacteria to isolate phages}

The K. pneumoniae isolates were used in spot assays with the caecum filtrate, which was

238 free of bacteria (as verified by Gram-stained smear and plating on nutrient agar; not shown).

239 Phages infecting these isolates were initially identified in the caecal effluent by spotting $10 \mu 1$

240 aliquots of filtered caecal effluent onto TSA overlays containing $200 \mu \mathrm{l}$ of a given culture in the

241 exponential phase of growth. Plaques identical to those shown in Fig. 1(a) were observed with all

$242 K$. pneumoniae isolates in the spot assays, and phages were present at $2 \times 10^{5} \pm 2.65 \times 10^{3}(n=3)$

$243 \mathrm{pfu} / \mathrm{ml}$ caecal effluent. Clear plaques of $2 \mathrm{~mm}$ diameter were visible within $3 \mathrm{~h}$ of spotting onto

244 an agar overlay. After prolonged incubation, the area around the plaques developed opaque

245 haloes presumably caused by depolymerase activity, which increased in size over the course of 4

246 days, although the central clear area of the plaques remained $2 \mathrm{~mm}$ in diameter (Fig. 1b). This

247 phenomenon has been observed previously for lytic phages of the families Siphoviridae,

248 Podoviridae and Myoviridae against K. pneumoniae, and is associated with degradation of

249 capsular polysaccharides (Geyer et al., 1983; Verma, Harjai \& Chhibber, 2009; Hsu et al., 2013;

250 Lin et al., 2014a; Shang et al., 2015). The non-Klebsiella isolates were not screened against the

251 caecum filtrate for phages. 
Strain L4-FAA5 was used as the host bacterium on which to isolate and propagate one

253

254

255

256

257

258

259

260

261

262

263

264

265

266

267

268

269

270

271

272

273

274

phage (which we named KLPN1) to purity. KLPN1 infected all K. pneumoniae isolates

recovered from the filter-sterilized caecal effluent.

The ability of phage KLPN1 to infect a panel of K. pneumoniae subsp. pneumoniae

clinical isolates was determined (Table 1), which revealed that all K2 strains tested (including

the type strain) were sensitive to this phage, though KLPN1 did not infect any of the other tested strains belonging to other capsular types. VNTR analysis showed that the six K2 isolates in the panel represented five, distinct strains, suggesting a wide susceptibility to the phage among isolates of this capsular type. In addition, it did not exhibit depolymerase activity with any of the clinical $\mathrm{K} 2$ isolates.

\section{Characterization of phage KLPN1}

Phage KLPN1 is chloroform-resistant. In addition, it displayed stability to prolonged storage in TSB at $4{ }^{\circ} \mathrm{C}$ : after 6 and 18 months' storage, titres for the phage were still $10^{10} \mathrm{pfu} / \mathrm{ml}$, comparable with the original stock. Transmission electron microscopy revealed the isometricheaded phage to possess a capsid of $\sim 62.7 \pm 2.3 \mathrm{~nm}(n=30)$ in diameter with a long noncontractile tail of $\sim 164.4 \pm 3.0 \mathrm{~nm}(n=29)$, thus indicating that this phage is a member of the family Siphoviridae (Fig. 2). Notably, the base-plate structure was unusual with a distinct central tail fibre [length $33.4 \pm 1.7 \mathrm{~nm}(n=43)]$ with apparently three elongated spherical structures

[length, $13.2 \pm 1.3 \mathrm{~nm}(n=43)$; width, $6.9 \pm 0.7 \mathrm{~nm}(n=48)$ ] loosely associated with the central regions of the tail fibre. This unique base-plate structures resembles a rosette with three leaves, and can be observed in all five micrographs shown in Figure 2. A similar structure has been described for Rtp, a lytic phage of Escherichia coli (Wietzorrek et al., 2006), with which KLPN1 
275 shares some sequence identity (discussed below). It is also visible in electron micrographs of 276 phage $\phi 28$, which infects K. pneumoniae capsular type K28 (Geyer et al., 1983).

277 It was straightforward to isolate high-quality DNA from phage KLPN1. Heating an 278 aliquot of CsCl-purified, DNAse-/RNAse-treated sample at $80^{\circ} \mathrm{C}$ for $10 \mathrm{~min}$ followed by $279 \mathrm{phenol} / \mathrm{chloroform} /$ isoamyl alcohol extractions and ethanol precipitation gave large quantities of 280 high-quality DNA that was used for restriction digests (not shown) and genome sequencing. The 281 estimated genome size of KLPN1 based on restriction digests with EcoRV or HaeIII was 45

$282 \mathrm{kbp}$, which was an underestimation of the genome size of 49,037 bp as determined by 283 sequencing (see below).

Sequence analysis of KLPN1

The genome of KLPN1 was 49,037 bp with a G+C content of $50.53 \%$, similar to

previously sequenced Klebsiella Siphoviridae phages such as KP36 (Table 2). Initial genome annotation was performed using Genemark (Besemer \& Borodovsky, 1999), from which a gff file was generated to allow visualisation of the predicted ORFs in Artemis v10.0 (Rutherford et al., 2000). Each ORF with a minimum amino acid content of 30 , a start and stop codon as well as a ribosomal-binding site was retained (Table 3). The genome of KLPN1 was predicted to encompass 73 ORFs divided into four clusters, two rightward and two leftward (Fig. 3, Table 3).

Of the 73 predicted ORFs, 23 were assigned a function with the remainder representing

294 hypothetical proteins with no assignable function (Table 3). BLAST analysis of the complete nucleotide sequence indicated that KLPN1 is closely related to the Klebsiella phages KP36 (95

$296 \%$ identity across $86 \%$ of the genome; Kęsik-Szeloch et al., 2013), F20 (84 \% identity across 82

$297 \%$ of the genome, GenBank accession no. JN672684; Mishra, Choi \& Kang, 2012) and phage 
2981513 (95\% identity across $85 \%$ of the genome, GenBank accession no. KP658157; Cao et al.,

299 2015). Furthermore, partial identity was observed against Shigella phage Shfll as well as

300 enterobacterial phages T1 (Roberts, Martin \& Kropinski, 2004) and RTP (Wietzorrek et al.,

301 2006) (GenBank accession numbers HM035024, AY216660 and AM156909, respectively). A

302 comparative analysis of KLPN1 was performed against both known members (KP36, F20) of the

303 genus "Kp36likevirus" (Niu et al., 2014; Table 3, Fig. 3). For completion, KLPN1 was also

304 compared with previously sequenced Klebsiella phages (Table 2). KLPN1 was shown not to

305 share detectable homology with Klebsiella phages belonging to the family Podoviridae or

306 Myoviridae. Based on the amino acid percentage identities presented in Table 3, the genomes of

307 KLPN1 and related phages were divided into functional conserved modules: packaging, phage

308 particle morphogenesis and DNA replication (Fig. 3, Table 3). Sections of the KLPN1 genome

309 were shown to exhibit homology to the Siphoviridae phage phiKO2 genome, although such

310 homology was confined to the tail morphogenesis region and one hypothetical protein (Table 3).

311 Of the 73 predicted ORFs, only three appeared unique to KLPN1: two genes encoding

312 hypothetical proteins located at the 5' end of the genome and a putative homing endonuclease-

313 gene positioned in the capsid morphogenesis module (Table 3).

314 Based on sequence homology to ORF33 (encoding the host-specificity J protein; InterPro

315 IPR021034) of phage T1, the phage receptor-binding protein of KLPN1 was predicted to be

316 encoded by ORF43. The deduced ORF43 protein was found to exhibit similarity to fibronectin

317 type III domain-containing protein, and potentially encodes the depolymerase whose effect was

318 observed on the phage assay plates (Fig. 1). However, a HHpred search with the protein

319 sequence encoded by this ORF failed to detect any domains associated with enzymes (such as

320 glycanases, deacetylases and lyases) associated with depolymerase activity of Klebsiella lytic 
321 phages (Geyer et al., 1983). The protein encoded by ORF34 of phage NTUH-K2044-K1-1 has

322 proven depolymerase activity associated with pectate lyase (Lin et al., 2014a); a HHpred search

323 confirmed the protein encoded by this ORF has a lyase/polygalacturonase domain (1ru4_A

324 pectate lyase, $94.3 \%$ probability of true positive, E-value 0.055 , P-value $1.6 \times 10^{-6}$; 1 bhe_A

325 PEHA, polygalacturonase, $90.1 \%$ probability of true positive, E-value 13, P-value 0.00038 ).

326 ORF96 of phage 0507-KN2-1 also encodes proven depolymerase activity (Hsu et al., 2013). A

327 HHpred search demonstrated the protein encoded by this ORF has an acetylneuraminidase

328 domain (3gw6_A endo- $N$-acetylneuraminidase, $99.8 \%$ probability of true positive, E-value

$3291 \times 10^{-19}$, P-value $2.9 \times 10^{-24}$ ). The whole-genome sequence of phage $\mathrm{P} 13$ cannot be retrieved from

330 GenBank; however, on the basis of a PSI-BLAST search conducted by Shang et al. (2015),

331 genes 49 and 50 of phage P13 are predicted to encode the exopolysaccharide depolymerase, but

332 no further substrate/functional information is available. HHpred searches of all proteins encoded

333 by KLPN1 showed that ORF34 and ORF35 encode an endo- $N$ -

334 acetylneuraminidase/endosialidase domain (Table 4). Consequently, we predict ORF34 and/or

335 ORF35 encode the depolymerase activity of phage KLPN1. Further work will be required to 336 confirm our hypothesis.

337 The proteins encoded by ORF36 and ORF36.1 are predicted to be two chaperones,

338 analogous to gpG and gpGT required for phage $\lambda$ tail assembly (Xu, Hendrix \& Duda, 2013).

339 These ORFs are believed to keep the tail tape measure protein (TMP) soluble and to recruit the

340 major tail protein subunits, both essential processes for tail assembly. ORF36 encodes the short

341 chaperone (gpG), while a programmed -1 translational frameshift facilitates a translational fusion

342 between the products of ORF36 and ORF36.1 so as to form the long chaperone (gpGT) (hence

343 the lack of a ribosome-binding site for ORF36.1) (Fig. 4). A BLASTP search of the predicted 
344213 aa fusion protein showed it shares $47 \%$ identity (E-value $\left.3 \times 10^{-56}\right)$ with the tape measure

345 chaperone of the Citrobacter Siphoviridae phage Stevie, reported to have a conserved

346 translational frameshift (Shaw et al., 2015; Fig. 4).

347 The genome sequence of KLPN1 was subjected to BLASTN searches against all publicly

348 available virome sequence data held by METAVIR [51,992,208 sequence reads associated with

34970 projects from a range of habitats, including human faeces (Reyes et al., 2010; Kim et al.,

350 2011; Minot et al., 2011, 2013); Supplementary Table 1]. No hits corresponding to KLPN1 were

351 found among these publicly available datasets. However, using InterProScan, the protein

352 sequence encoded by ORF64 was found to belong to the family 'Protein of unknown function

353 DUF3987', representing uncharacterized human-gut-microbiome-specific proteins (Ellrott et al., 354 2010; Table 3).

355

356

357 DISCUSSION

358

K. pneumoniae subsp. pneumoniae is an enteric bacterium and important nosocomial and community-acquired opportunistic pathogen, causing pneumonia, and wound, burn, urinary tract

360 and blood infections. There are 79 recognized capsular types of $K$. pneumoniae subsp.

361 pneumoniae, with capsular types $\mathrm{K} 1, \mathrm{~K} 2, \mathrm{~K} 5, \mathrm{~K} 54$ and $\mathrm{K} 57$ most frequently associated with

362 invasive disease or pathogenicity; capsular type K20 is much rarer, though there is regional

363 variability in the predominant clinically relevant capsular types (Turton et al., 2010; Pan et al.,

364 2013; Hsu et al., 2013). It has been suggested that the majority of $K$. pneumoniae-associated

365 liver infections are preceded by colonization of the gastrointestinal tract, and one study has

366 demonstrated familial spread of a virulent clone of $K$. pneumoniae causing liver disease (Harada 
367 et al., 2011; Lin et al., 2012). Using caecal effluent recovered from a healthy woman, we have

368 isolated a capsular type $\mathrm{K} 2 \mathrm{rmp} A^{+}$strain (L4-FAA5) of $K$. pneumoniae subsp. pneumoniae. After

$369 \mathrm{~K} 1, \mathrm{~K} 2$ strains are most frequently associated with pyogenic liver abscesses and frequently

370 associated with community-acquired pneumonia (Lin et al., 2014b). K1 and K2 strains, along

371 with the $r m p A$ (regulator of mucoid phenotype A) gene, are associated with hypermucoviscosity

372 and virulence. A study examining K1 and K2 strains of $K$. pneumoniae in 43 Taiwanese patients

373 with liver abscesses showed, using pulsed-field gel electrophoresis (PFGE), that 17 randomly

374 selected pairs of patient faecal or saliva and abscess isolates allowed differentiation of patients

375 based on the PFGE profiles of their isolates. The abscess isolates had PFGE profiles identical, or

376 closely related to, those of faecal or saliva isolates from the same patient (Fung et al., 2012). The

377 similarity between each patient's faecal and abscess PFGE profiles led Fung et al. (2012) to

378 suggest that the patients' infections arose from bacteria originating in the gut microbiota. Our

379 isolation of a K. pneumoniae strain with virulence traits from the human caecum supports the

380 assertion that the human gut microbiota is a source of potentially infectious $K$. pneumoniae.

381 Limited data are available on the carriage and diversity of gut/faecal K. pneumoniae. A study on

382 healthy Chinese adults in Chinese territories and overseas showed between 18.8 and $87.7 \%$

383 faecal carriage of K. pneumoniae, with individuals in Malaysia (64/73) and Taiwan (150/200)

384 showing the highest carriage rates and those in Japan (6/32) showing the lowest (Lin et al.,

385 2012). Isolates were tested with antisera for capsular types K1-K74 and K80-82: K1 and K2

386 isolates accounted for $\sim 10 \%$ of isolates in all countries, at least one representative of each

387 capsular type was detected in the study and non-typable (11-88 \%) isolates were reported for $7 / 8$

388 countries (Lin et al., 2012). The high carriage of K. pneumoniae in Taiwan is thought to

389 contribute to the high incidence of liver abscess disease seen in the country (Fung et al., 2012). 
As with other nosocomial opportunistic pathogens, broad-spectrum antibiotic resistance

391 is a feature of K. pneumoniae subsp. pneumoniae and limits treatment options (Cantón et al.,

392 2012). Therefore, identification of alternative treatment therapies or adjuncts to existing

393 therapies for infections associated with this organism is of utmost importance. Phages against $K$.

394 pneumoniae subsp. pneumoniae have been used to successfully treat K. pneumoniae infections in

395 animal models of sepsis, pneumonia, burn wounds and liver disease, without causing apparent

396 harm to animals (Bogovazova, Voroshilova \& Bondarenko, 1991; Malik \& Chhibber, 2009;

397 Chhibber et al., 2010; Kumari, Harjai \& Chhibber, 2009; Kumari, Harjai \& Chhibber, 2010b;

398 Hung et al., 2011). The number of known lytic phages that infect $K$. pneumoniae remains small

399 and their range is limited to a small number of capsular types (though phenotypic information on

400 strains is absent from the majority of publications on $K$. pneumoniae phages). Given the large

401 number of phages present in faeces and caecal effluent (Hoyles et al., 2014), and because $K$.

402 pneumoniae subsp. pneumoniae is a member of the human gut microbiota, we were keen to

403 exploit this environment as a source of phages with potential therapeutic applications. We

404 isolated from caecal effluent a phage (named KLPN1) that infects K. pneumoniae subsp.

405 pneumoniae L4-FAA5 and K2 clinical isolates of $K$. pneumoniae subsp. pneumoniae (Table 1).

406 Phage KLPN1 does not infect non-K2 clinical isolates (Table 1). To the best of our knowledge,

407 this is the first report of the isolation of a bacterium-phage combination from the human caecum.

408 To date, only eight phages infecting the K2 capsular type of $K$. pneumoniae have been

409 reported (Bogovazova, Voroshilova \& Bondarenko, 1991; Malik \& Chhibber, 2009; Chhibber et

410 al., 2010; Kumari, Harjai \& Chhibber, 2010b; Hung et al., 2011). Several Podoviridae were

411 isolated on K. pneumoniae B5055 (assumed to be derived from NCTC 5055) and tested as

412 therapeutic agents [Kpn5, Kpn12, Kpn13, Kpn17, Kpn22 (individually and in cocktail) and 
$413 \mathrm{KØ1]}$ in B5055-induced burn-wound infections in mice (Kumari, Harjai \& Chhibber, 2009;

414 Kumari, Harjai \& Chhibber, 2010a; Kumari, Harjai \& Chhibber, 2010b; Malik \& Chhibber, 415 2009). Phage SS (Podoviridae) was isolated on B5055 and used to treat lobar pneumonia caused 416 by the same strain in mice (Chhibber et al., 2010). Phage $\varphi$ NK5 (Podoviridae) was isolated from 417 sewage on K. pneumoniae NK-5, isolated from a patient with a primary liver abscess and 418 septicaemia (Hung et al., 2011). The same bacterial strain was used to induce liver abscesses and 419 bacteraemia in mice, which were successfully treated with $\varphi \mathrm{NK} 5$. None of the aforementioned 420 phages has been tested against a range of clinical K. pneumoniae isolates. Therefore, it is 421 difficult to assess how useful they would be in treatment of a wide range of clinical infections, 422 especially when similar infections can be caused by different capsular types of K. pneumoniae 423 (e.g. Table 1). We can state that KLPN1 has potential for treating K2-associated infections, but 424 note that differences in lytic infection were observed between the caecal isolate and the clinical 425 isolates: KLPN1 infected the caecal isolate and exhibited depolymerase activity that was absent 426 with the clinical K2 isolates. Further investigations may reveal that its infection kinetics differ 427 between K2 strains.

$428 \quad$ Hung et al. (2011) demonstrated the generation of phage-insensitive mutants after 6 and $42912 \mathrm{~h}$ co-cultures of NK-5/ $\varphi \mathrm{NK} 5$, with these mutants lacking the hypermucoviscosity phenotype 430 of NK-5. On solid media, phage-insensitive mutants of $K$. pneumoniae L4-FAA5 were routinely 431 observed after $48 \mathrm{~h}$ incubation with phage KLPN1. Whether mutants are generated more quickly 432 in liquid culture remains to be determined, as does the nature of the mutations that allow them to 433 escape lytic infection with KLPN1. Does solid media act as a spatial refuge (Mills et al., 2013) 434 for sensitive bacteria, delaying the appearance of insensitive mutants? 
It is predicted that many members of the human gut microbiota are embedded in biofilms,

436

437

438

439

440

441

442

443

444

445

446

447

448

449

450

451

452

453

454

455

456 457

and phages may contribute to cell lysis in these ecological niches (Mills et al., 2013). The

microbiota of the human caecum resides in a highly mucoid biofilm (Randal Bollinger et al., 2007). Phage KLPN1 exhibits depolymerase activity on K. pneumoniae L4-FAA5, which may

facilitate the movement of the phage within the caecal biofilm. It has been demonstrated that phages can diffuse within biofilms, be immobilized, amplified and released after a lytic cycle in these environments. They may also potentially interact with their specific binding sites on bacteria, even in the absence of lytic activity (Mills et al., 2013). Further work is needed to understand interactions between K. pneumoniae L4-FAA5 and phage KLPN1 in single- and multi-strain biofilm systems, and to determine whether the "spatial refuge hypothesis" (Mills et al., 2013) holds for the caecal microbiota, preventing the extinction of all sensitive bacteria within the biofilm.

Following whole-genome sequencing and annotation, KLPN1 was found to encompass 73 ORFs and, based on its sequence homology to Klebsiella phages KP36 and F20, it is evident that KLPN1 is a member of the family Siphoviridae, subfamily Tunavirinae, and would become the third member of the genus "Kp36likevirus" (Niu et al., 2014). In addition, based on our sequence analyses phage 1513 (a Siphoviridae that infects a multidrug-resistant K. pneumoniae strain isolated from a patient with pneumonia; Cao et al., 2015) can also be added to this genus, bringing the total number of members to four. This classification would be consistent with the morphological appearance of KLPN1, which has a capsid of $64 \mathrm{~nm}$ as well as rosette-like or propeller tail tip, a finding also observed for phages $\phi 28, \mathrm{~T} 1$ and RTP (Geyer et al., 1983;

Wietzorrek et al., 2006). Unsurprisingly, KLPN1 shares no sequence homology with Klebsiella phages belonging to the families Myoviridae or Podoviridae; however, some similarities to 
Siphoviridae phage phiKO2 were observed, but these were confined to the tail morphogenesis

459 region and a hypothetical protein. ORF60 and ORF61 are predicted to encode holin (which

460 destroys the cytoplasmic membrane) and endolysin (which degrades peptidoglycan),

461 respectively. These gene products have antibacterial properties that can be used in phage-

462 associated therapies (Viertel, Ritter \& Horz, 2014); therefore, further characterization of the

463 proteins encoded by these ORFs is required.

464

465

466

\section{CONCLUSIONS}

We isolated a K. pneumoniae subsp. pneumoniae-phage combination from the human caecum, and have characterized its lytic properties against a panel of $K$. pneumoniae subsp. pneumoniae clinical isolates. Phage KLPN1 infects capsular type K2 isolates, and may have applications in treating a range of $\mathrm{K} 2$-associated infections. We have, therefore, demonstrated the gut microbiota as a source of clinically relevant phages. Whole-genome sequence analysis of KLPN1 revealed the phage to encode proteins that have potential applications in phageassociated therapies. Characterization of these gene products, or genetically modified variants, is required to determine their usefulness.

\section{ACKNOWLEDGEMENTS}




\section{REFERENCES}

483 Altschul SF, Gish W, Miller W, Myers EW, Lipman DJ. 1990. Basic local alignment search tool. 484 Journal of Molecular Biology 215:403-410.

485 Besemer J, Borodovsky M. 1999. Heuristic approach to deriving models for gene finding. 486 Nucleic Acids Research 27:3911-3920.

487 Bogovazova GG, Voroshilova NN, Bondarenko VM. 1991. The efficacy of Klebsiella 488 pneumoniae bacteriophage in the therapy of experimental Klebsiella infection. Zhurnal 489 Mikrobiologii Epidemiologii i Immunobiologii 4:5-8.

490 Breitbart M, Hewson I, Felts B, Mahaffy JM, Nulton J, Salamon P, Rohwer F. 2003.

491 Metagenomic analyses of an uncultured viral community from human feces. Journal of 492 Bacteriology 185:6220-6223.

493 Breitbart M, Haynes M, Kelley S, Angly F, Edwards RA, Felts B, Mahaffy JM, Mueller J, 494 Nulton J, Rayhawk S, Rodriguez-Brito B, Salamon P, Rohwer F. 2008. Viral diversity and 495 dynamics in an infant gut. Research in Microbiology 159:367-373.

496 Cao F, Wang X, Wang L, Li Z, Che J, Wang L, Li X, Cao Z, Zhang J, Jin L, Xu Y. 2015.

497 Evaluation of the efficacy of a bacteriophage in the treatment of pneumonia induced by 498 multidrug resistance Klebsiella pneumoniae in mice. BioMed Research International 499 2015:752930. doi: 10.1155/2015/752930.

500 Cantón R, Akóva M, Carmeli Y, Giske CG, Glupczynski Y, Gniadkowski M, Livermore DM, 501 Miriagou V, Naas T, Rossolini GM, Samuelsen Ø, Seifert H, Woodford N, Nordmann P, 502 European Network on Carbapenemases. 2012. Rapid evolution and spread of carbapenemases 503 among Enterobacteriaceae in Europe. Clinical Microbiology and Infection 18:413-431. 
504 Carrër A, Poirel L, Eraksoy H, Cagatay AA, Badur S, Nordmann P. 2008. Spread of OXA-48-

505 positive carbapenem-resistant Klebsiella pneumoniae isolates in Istanbul, Turkey. Antimicrobial

506 Agents and Chemotherapy 52:2950-2954.

507 Casjens SR, Gilcrease EB, Huang WM, Bunny KL, Pedulla ML, Ford ME, Houtz JM, Hatfull

508 GF, Hendrix RW. 2004. The pKO2 linear plasmid prophage of Klebsiella oxytoca. Journal of

509 Bacteriology 186:1818-1832.

510 Chun J, Lee J-H, Jung Y, Kim M, Kim S, Kim BK, Lim YW. 2007. EzTaxon: a web-based tool

511 for the identification of prokaryotes based on $16 \mathrm{~S}$ ribosomal gene sequences. International

512 Journal of Systematic and Evolutionary Microbiology 57:2259-2261.

513 Cui Z, Shen W, Wang Z, Zhang H, Me R, Wang Y, Zeng L, Zhu Y, Qin J, He P, Guo X. 2012.

514 Complete genome sequence of Klebsiella pneumoniae phage JD001. Journal of Virology

$51586: 13843$.

516 Drulis-Kawa Z, Mackiewicz P, Kęsik-Szeloch A, Maciaszczyk-Dziubinska E, Weber-

517 Dąbrowska B, Dorotkiewicz-Jach A, Augustyniak D, Majkowska-Skrobek G, Bocer T, Empel J,

518 Kropinski AM. 2011. Isolation and characterisation of KP34 - a novel $\varphi$ KMV-like

519 bacteriophage for Klebsiella pneumoniae. Applied Microbiology and Biotechnology 90:1333-

5201345.

521 Ellrott K, Jaroszewski L, Li W, Wooley JC, Godzik A. 2010. Expansion of the protein repertoire 522 in newly explored environments: human gut microbiome specific protein families. PLoS

523 Computational Biology 6:e1000798.

524 Fung CP, Lin YT, Lin JC, Chen TL, Yeh KM, Chang FY, Chuang HC, Wu HS, Tseng CP, Siu

525 LK. 2012. Klebsiella pneumoniae in gastrointestinal tract and pyogenic liver abscess. Emerging

526 Infectious Diseases 18:1322-1325. 
527 Geyer H, Himmelspach K, Kwiatkowski B, Schlecht S, Stirm S. 1983. Degradation of bacterial

528 surface carbohydrates by virus-associated enzymes. Pure and Applied Chemistry 55:637-653.

529 Harada S, Tateda K, Mitsui H, Hattori Y, Okubo M, Kimura S, Sekigawa K, Kobayashi K,

530 Hashimoto N, Itoyama S, Nakai T, Suzuki T, Ishii Y, Yamaguchi K. 2011. Familial spread of a

531 virulent clone of Klebsiella pneumoniae causing primary liver abscess. Journal of Clinical

532 Microbiology 49:2354-2356.

533 Hoyles L, McCartney AL, Neve H, Gibson GR, Sanderson JD, Heller KJ, van Sinderen D. 2014.

534 Characterization of virus-like particles associated with the human faecal and caecal microbiota.

535 Research in Microbiology 165:803-812.

536 Hsu CR, Lin TL, Pan YJ, Hsieh PF, Wang JT. 2013. Isolation of a bacteriophage specific for a

537 new capsular type of Klebsiella pneumoniae and characterization of its polysaccharide

538 depolymerase. PLoS One 8:e70092.

539 Hung $\mathrm{CH}$, Kuo CF, Wang CH, Wu CM, Tsao N. 2011. Experimental phage therapy in treating

540 Klebsiella pneumoniae-mediated liver abscesses and bacteremia in mice. Antimicrobial Agents

541 and Chemotherapy 55:1358-1365.

542 Jamal M, Hussain T, Das CR, Andleeb S. 2015. Characterization of Siphoviridae phage Z and

543 studying its efficacy against multi-drug resistant MDR Klebsiella pneumoniae planktonic cells

544 and biofilm. Journal of Medical Microbiology 64:454-462.

545 Karumidze N, Kusradze Ia, Rigvava S, Goderdzishvili M, Rajakumar K, Alavidze Z. 2013.

546 Isolation and characterisation of lytic bacteriophages of Klebsiella pneumoniae and Klebsiella

547 oxytoca. Current Microbiology 66:251-258.

548 Kęsik-Szeloch A, Drulis-Kawa Z, Weber-Dąbrowska B, Kassner J, Majkowska-Skrobek G,

549 Augustyniak D, Lusiak-Szelachowska M, Zaczek M, Górski A, Kropinski A M. 2013. 
550 Characterising the biology of novel lytic bacteriophages infecting multidrug resistant Klebsiella

551 pneumoniae. Virology Journal 10:100.

552 Kim MS, Park EJ, Roh SW, Bae JW. 2011. Diversity and abundance of single-stranded DNA

553 viruses in human feces. Applied and Environmental Microbiology 77:8062-8070.

554 Kumari S, Harjai K, Chhibber S. 2009. Efficacy of bacteriophage treatment in murine burn

555 wound infection induced by Klebsiella pneumoniae. Journal of Microbiology and Biotechnology $556 \quad 19: 622-628$.

557 Kumari S, Harjai K, Chhibber S. 2010a. Isolation and characterization of Klebsiella pneumoniae 558 specific bacteriophages from sewage samples. Folia Microbiologica Praha 55:221-227.

559 Kumari S, Harjai K, Chhibber S. 2010b. Evidence to support the therapeutic potential of

560 bacteriophage Kpn5 in burn wound infection caused by Klebsiella pneumoniae in BALB/c mice.

561 Journal of Microbiology and Biotechnology 20:935-941.

562 Lepage P, Colombet J, Marteau P, Sime-Ngando T, Doré J, Leclerc M. 2008. Dysbiosis in

563 inflammatory bowel disease: a role for bacteriophages? Gut 57:424-425.

564 Lin YT, Siu LK, Lin JC, Chen TL, Tseng CP, Yeh KM, Chang FY, Fung CP. 2012.

565 Seroepidemiology of Klebsiella pneumoniae colonizing the intestinal tract of healthy Chinese

566 and overseas Chinese adults in Asian countries. BMC Microbiology 12:13.

567 Lin TL, Hsieh PF, Huang YT, Lee WC, Tsai YT, Su PA, Pan YJ, Hsu CR, Wu MC, Wang JT.

568 2014a. Isolation of a bacteriophage and its depolymerase specific for K1 capsule of Klebsiella

569 pneumoniae: implication in typing and treatment. Journal of Infectious Diseases 210:1734-1744.

570 Lin JC, Koh TH, Lee N, Fung CP, Chang FY, Tsai YK, Ip M, Siu LK. 2014b. Genotypes and

571 virulence in serotype K2 Klebsiella pneumoniae from liver abscess and non-infectious carriers in

572 Hong Kong, Singapore and Taiwan. Gut Pathogens 6:21. 
573 Luo CH, Chiou PY, Yang CY, Lin NT. 2012. Genome, integration, and transduction of a novel

574 temperate phage of Helicobacter pylori. Journal of Virology 86:8781-8792.

575 Malik R, Chhibber S. 2009. Protection with bacteriophage KØ1 against fatal Klebsiella

576 pneumoniae-induced burn wound infection in mice. Journal of Microbiology Immunology and

577 Infection 42:134-140.

578 Mills S, Shanahan F, Stanton C, Hill C, Coffey A, Ross RP. 2013. Movers and shakers: influence

579 of bacteriophages in shaping the mammalian gut microbiota. Gut Microbes 4:4-16.

580 Minot S, Sinha R, Chen J, Li H, Keilbaugh SA, Wu GD, Lewis JD, Bushman FD. 2011. The

581 human gut virome: inter-individual variation and dynamic response to diet. Genome Research

$582 \quad 21: 1616-1625$.

583 Minot S, Bryson A, Chehoud C, Wu GD, Lewis JD, Bushman FD. 2013. Rapid evolution of the

584 human gut virome. Proceedings of the National Academy of Sciences U S A 110:12450-12455.

585 Mishra CK, Choi TJ, Kang SC. 2012. Isolation and characterization of a bacteriophage F20

586 virulent to Enterobacter aerogenes. Journal of General Virology 93:2310-2314.

587 Niu YD, McAllister TA, Nash JH, Kropinski AM, Stanford K. 2014. Four Escherichia coli

588 O157:H7 phages: a new bacteriophage genus and taxonomic classification of T1-like phages.

589 PLoS One 9:e100426.

590 Pan YJ, Lin TL, Chen YH, Hsu CR, Hsieh PF, Wu MC, Wang JT. 2013. Capsular types of

591 Klebsiella pneumoniae revisited by wzc sequencing. PLoS One 8:e80670.

592 Pan YJ, Lin TL, Lin YT, Su PA, Chen, CT, Hsieh PF, Hsu CR, Chen CC, Hsieh YC, Wang JT.

593 2015. Identification of capsular types in carbapenem-resistant Klebsiella pneumoniae strains by

$594 w z c$ sequencing and implications for capsule depolymerase treatment. Antimicrobial Agents and

595 Chemotherapy 59:1038-1047. 
596 Pell LG, Kanelis V, Donaldson LW, Howell PL, Davidson AR. 2009. The phage lambda major

597 tail protein structure reveals a common evolution for long-tailed phages and the type VI bacterial

598 secretion system. Proceedings of the National Academy of Sciences U S A 106:4160-4165.

599 Randal Bollinger R, Barbas AS, Bush EL, Lin SS, Parker W. 2007. Biofilms in the large bowel

600 suggest an apparent function of the human vermiform appendix. Journal of Theoretical Biology

$601 \quad 249: 826-831$.

602 Reyes A, Haynes M, Hanson N, Angly FE, Heath AC, Rohwer F, Gordon JI. 2010. Viruses in

603 the faecal microbiota of monozygotic twins and their mothers. Nature 466:334-338.

604 Reyes A, Semenkovich NP, Whiteson K, Rohwer F, Gordon JI. 2012. Going viral: next-

605 generation sequencing applied to phage populations in the human gut. Nature Reviews

606 Microbiology 10:607-617.

607 Roberts MD, Martin NL, Kropinski AM. 2004. The genome and proteome of coliphage T1.

608 Virology 318:245-266.

609 Roux S, Faubladier M, Mahul A, Paulhe N, Bernard A, Debroas D, Enault F. 2011. Metavir: a

610 web server dedicated to virome analysis. Bioinformatics 27:3074-3075.

611 Rutherford K, Parkhill J, Crook J, Horsnell T, Rice P, Rajandream MA, Barrell B. 2000.

612 Artemis: sequence visualization and annotation. Bioinformatics 16:944-945.

613 Schulz EC, Neumann P, Gerardy-Schahn R, Sheldrick GM, Ficner R. 2010. Structure analysis of

614 endosialidase NF at $0.98 \AA \AA$ resolution. Acta Crystallographica section D Biological

615 Crystallography 66:176-180.

616 Shang A, Liu Y, Wang J, Mo Z, Li G, Mou H. 2015. Complete nucleotide sequence of Klebsiella

617 phage P13 and prediction of an EPS depolymerase gene. Virus Genes 50:118-128.

618 Shaw JP, Aviles Medina CA, Chen Y, Luna AJ, Hernandez AC, Kuty Everett GF. 2015. 
619 Complete genome of Citrobacter freundii siphophage Stevie. Genome Announcements DOI

$620 \quad 10.1128 /$ genomeA.01434-14.

621 Šimoliūnas E, Kaliniene L, Truncaite L, Klausa V, Zajančkauskaite A, Meškys R. 2012. Genome 622 of Klebsiella sp.-infecting bacteriophage vB_KleM_RaK2. Journal of Virology 86:5406.

623 Souza KA, Ginoza HS, Haight RD. 1972. Isolation of a polyvalent bacteriophage for Escherichia 624 coli, Klebsiella pneumoniae, and Aerobacter aerogenes. Journal of Virology 9:851-856.

625 Turton JF, Perry C, Elgohari S, Hampton CV. 2010. PCR characterization and typing of 626 Klebsiella pneumoniae using capsular type-specific, variable number tandem repeat and 627 virulence gene targets. Journal of Medical Microbiology 59:541-547.

628 Vejborg RM, Friis C, Hancock V, Schembri MA, Klemm P. 2010. A virulent parent with 629 probiotic progeny: comparative genomics of Escherichia coli strains CFT073, Nissle 1917 and 630 ABU 83972. Molecular Genetics and Genomics 283:469-484.

631 Ventura M, Lee JH, Canchaya C, Zink R, Leahy S, Moreno-Munoz JA, O'Connell-Motherway 632 M, Higgins D, Fitzgerald GF, O'Sullivan DJ, van Sinderen D. 2005. Prophage-like elements in 633 bifidobacteria: insights from genomics, transcription, integration, distribution, and phylogenetic 634 analysis. Applied and Environmental Microbiology 71:8692-8705.

635 Verma V, Harjai K, Chhibber S. 2009. Characterization of a T7-like lytic bacteriophage of 636 Klebsiella pneumoniae B5055: a potential therapeutic agent. Current Microbiology 59:274-281.

637 Villion M, Moineau S. 2009. Bacteriophages of lactobacillus. Frontiers in Biosciences 638 Landmark Edition 14:1661-1683.

639 Viertel TM, Ritter K, Horz HP. 2014. Viruses versus bacteria-novel approaches to phage therapy 640 as a tool against multidrug-resistant pathogens. Journal of Antimicrobial Chemotherapy $641 \quad 69: 2326-2336$. 
642 Wagner J, Maksimovic J, Farries G, Sim WH, Bishop RF, Cameron DJ, Catto-Smith AG,

643 Kirkwood CD. 2013. Bacteriophages in gut samples from pediatric Crohn's disease patients:

644 metagenomic analysis using 454 pyrosequencing. Inflammatory Bowel Diseases 19:1598-1608.

645 Wietzorrek A, Schwarz H, Herrmann C, Braun V. 2006. The genome of the novel phage Rtp,

646 with a rosette-like tail tip, is homologous to the genome of phage T1. Journal of Bacteriology

$647 \quad 188: 1419-1436$.

648 Wu LT, Chang SY, Yen MR, Yang TC, Tseng YH. 2007. Characterization of extended-host-

649 range pseudo-T-even bacteriophage Kpp95 isolated on Klebsiella pneumoniae. Applied and

650 Environmental Microbiology 73:2532-2340.

651 Xu J, Hendrix RW, Duda RL. 2013. A balanced ratio of proteins from gene $G$ and frameshift652 extended gene $G T$ is required for phage lambda tail assembly. Journal of Molecular Biology $653 \quad 425: 3476-3487$.

654 
1

Figure 1

Appearance of plaques formed on $K$. pneumoniae subsp. pneumoniae L4-FAA5 by phage KLPN1. (a) Initial isolation of phages from filtered caecal effluent on TSA. (b) Appearance of plaques of pure phage stock after $24 \mathrm{~h}$. (c) Growth of haloes surrounding plaques over the course of the course of $96 \mathrm{~h}$. After $48 \mathrm{~h}$, presumed phage-insensitive mutants can be seen growing in the haloes surrounding the plaques. Images are shown to scale. 


\section{(b)}

\section{(a)}

(c)

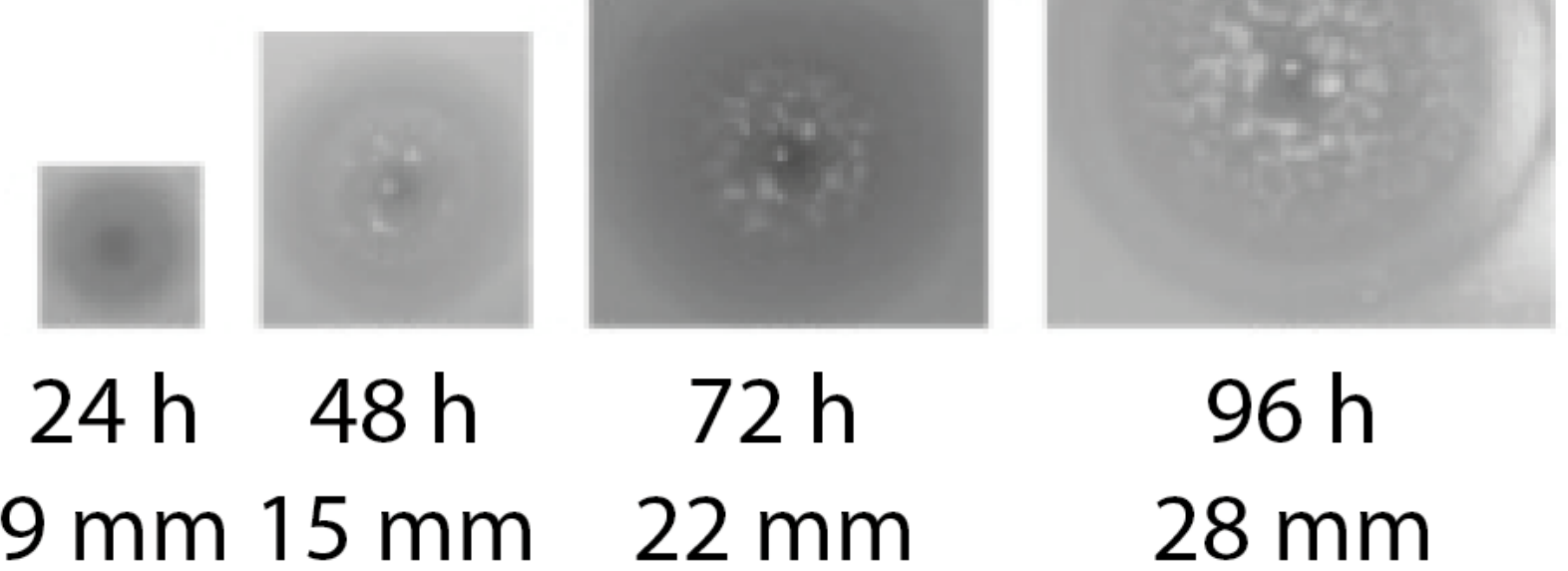


2

Figure 2

Transmission electron micrographs of phage KLPN1. The phage belongs to the family Siphoviridae, and has an unusual base-plate structure, resembling a rosette. The arrows indicate the central tail fibre surrounded by three flexible spherical base-plate structures.
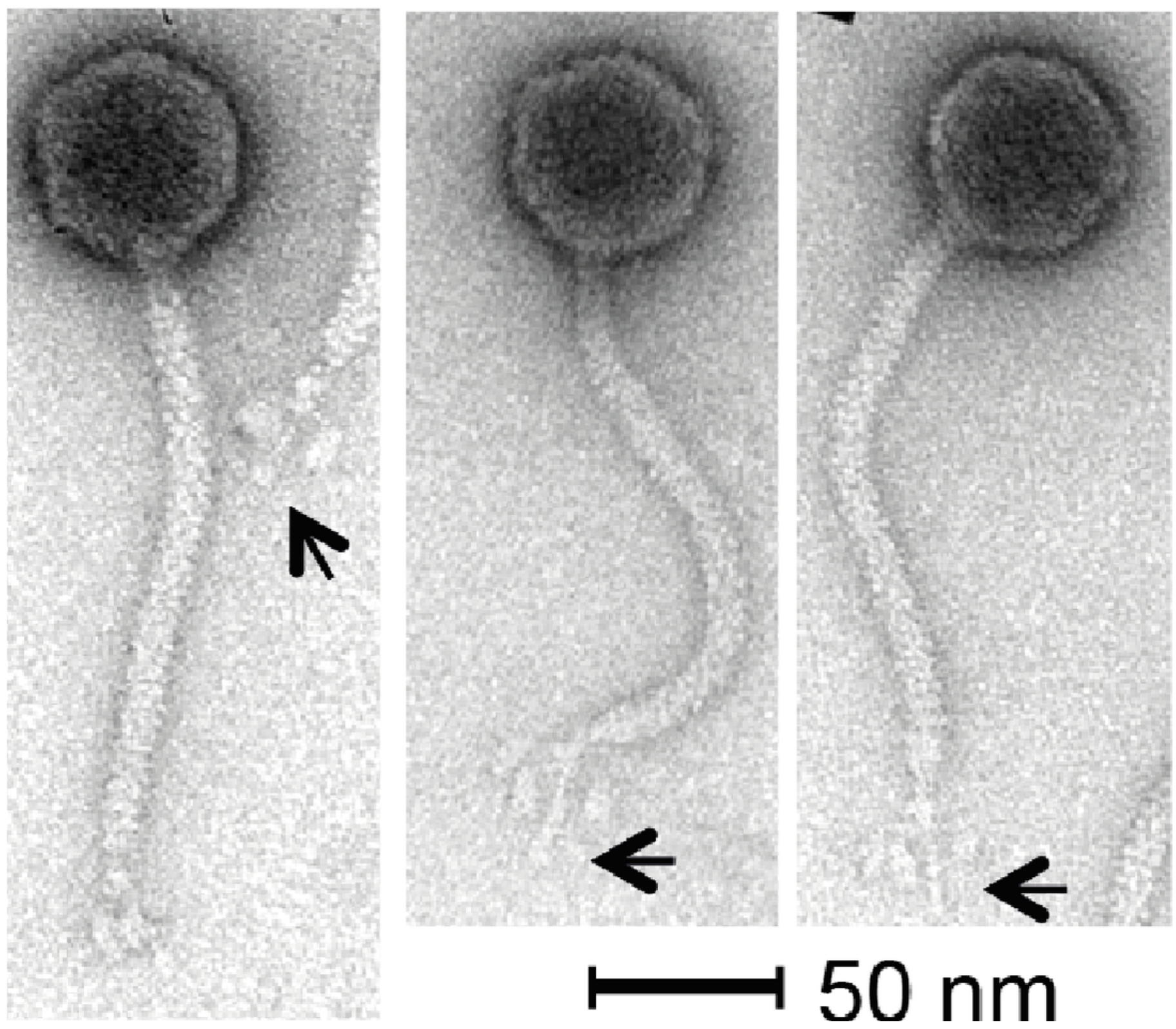


\section{3}

Figure 3

Genome structures of the four members of the genus "Kp36likevirus". Phages KLPN1, KP36 and 1513 are virulent to $K$. pneumoniae, while F20 is virulent to Enterobacter aerogenes (Mishra, Choi \& Kang, 2012).
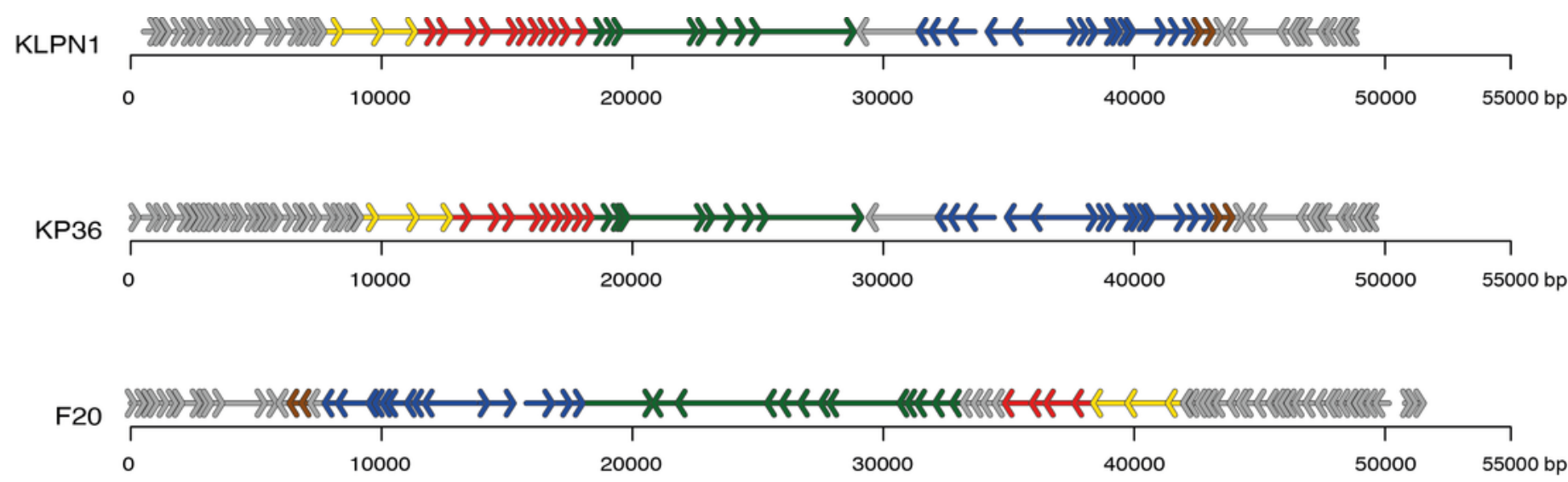

1513

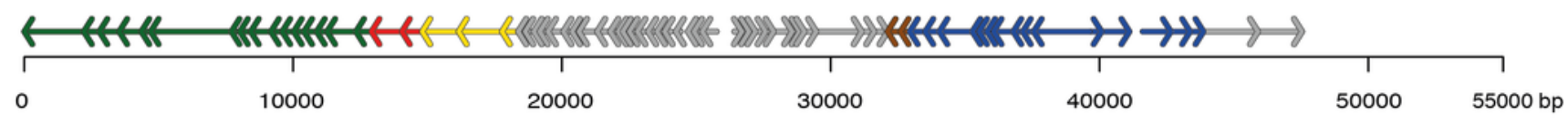

Unclassified

Head structure

Replication

Packaging

- Tail structure

- Cell lysis 
Figure 4

ORF36 and ORF36.1 are related by a programmed -1 translational frameshift. The frameshift allows translation of a gpGT-like protein (Xu, Hendrix \& Duda, 2013). The ORF36/ORF36.1 fusion protein is predicted to contain almost the entire sequence of ORF36. Citrobacter Siphoviridae phage Stevie (GenBank accession number KM236241) has a conserved translational frameshift in its tape measure chaperone (GenBank accession number AIX12284) (Shaw et al., 2015).
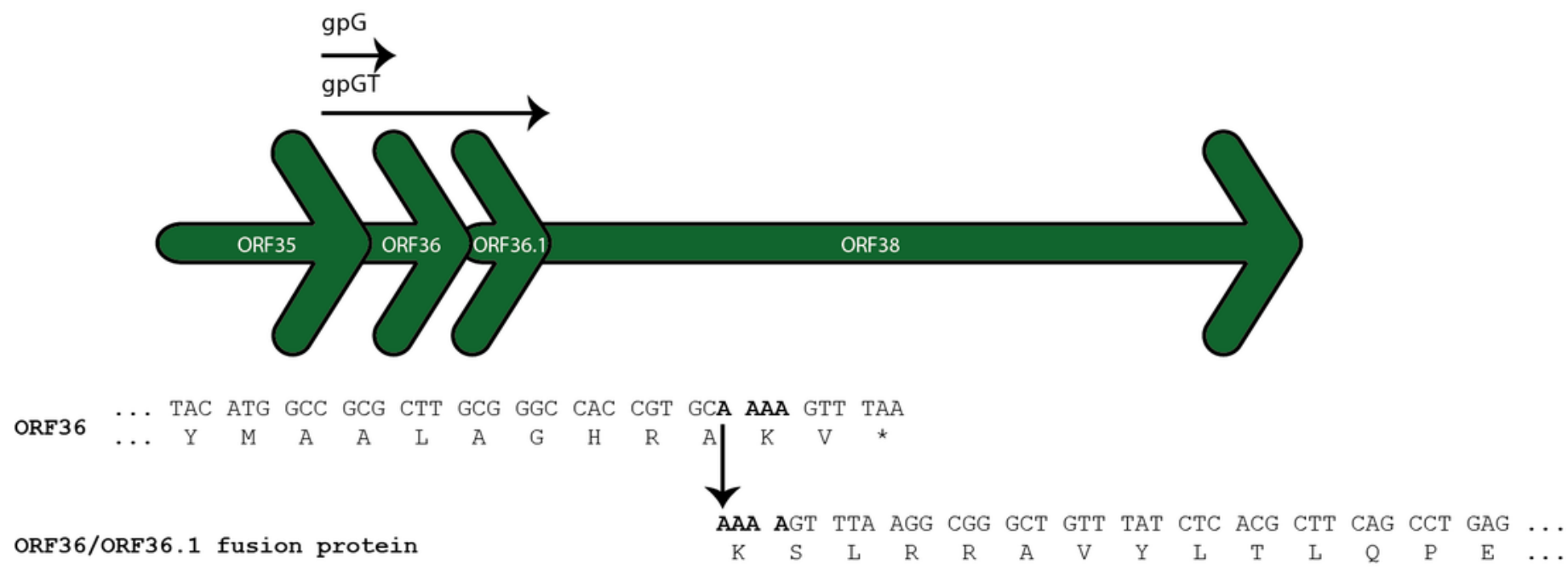

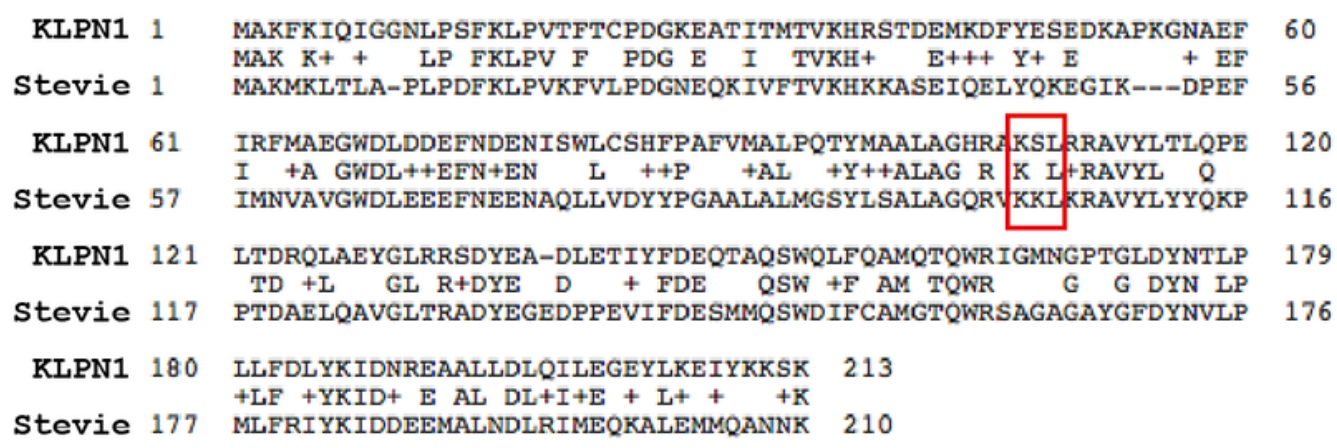




\section{Table $\mathbf{1}$ (on next page)}

Table 1 - Description of K. pneumoniae subsp. pneumoniae isolates against which phage KLPN1 was screened 
2 Table 1. Description of K. pneumoniae subsp. pneumoniae isolates against which phage KLPN1

3 was screened

4

\begin{tabular}{|c|c|c|c|c|c|}
\hline Strain* & $\begin{array}{c}\text { Capsular type (K PCR } \\
\text { result) } \dagger\end{array}$ & rmpA & $w c a G$ & Source & $\begin{array}{c}\text { Infected by phage } \\
\text { KLPN1 }\end{array}$ \\
\hline L4-FAA5 & $\mathrm{K} 2$ & + & - & Human caecal effluent & Yes \\
\hline $\mathrm{K} / 5216$ & $\begin{array}{l}\text { K1 (K1 cluster of } \\
\text { CC23) }\end{array}$ & + & + & Liver abscess (Taiwan) & No \\
\hline $\begin{array}{l}\text { NCTC } \\
5055\end{array}$ & K2 (reference strain) & + & - & Human & Yes§ \\
\hline $\begin{array}{l}\text { NCTC } \\
9660\end{array}$ & K5 (reference strain) & - & - & Cloacae of horse & No \\
\hline PHE1 & - & - & - & Rectal swab & No \\
\hline PHE2 & - & - & - & Human clinical & No \\
\hline PHE3 & - & - & - & Sputum, transplant patient & No \\
\hline PHE4 & - & - & - & Urine, spinal injury patient & No \\
\hline PHE5 & - & - & - & Human blood & No \\
\hline PHE6 & - & - & + & Urine, incontinent patient & No \\
\hline PHE7 & - & - & - & Human clinical & No \\
\hline PHE8 & - & - & - & Human blood & No \\
\hline PHE9 & - & - & - & Human clinical & No \\
\hline PHE10 & - & - & - & Human blood & No \\
\hline PHE11† & $\mathrm{K} 2$ & - & - & Blood, patient with urinary tract infection & Yes§ \\
\hline PHE12‡ & $\mathrm{K} 2$ & - & - & Urine & Yes§ \\
\hline PHE13 & K2 & - & - & $\begin{array}{l}\text { Blood and sputum, patient with } \\
\text { bacteraemia and pneumonia }\end{array}$ & Yes§ \\
\hline PHE14 & $\mathrm{K} 2$ & + & - & Sputum, patient with bacteraemia & Yes§ \\
\hline PHE15 & $\mathrm{K} 2$ & - & - & Urine, cardiac patient & Yes§ \\
\hline PHE16 & K20 & + & - & Sputum, transplant patient & No \\
\hline PHE17 & K54 & - & + & Intensive care unit & No \\
\hline PHE18 & K57 & - & - & Sputum, transplant patient & No \\
\hline
\end{tabular}

5 nd, No data.

6 *Strains with the prefix PHE were submitted for typing by healthcare providers to Public Health

7 England - Colindale. Each isolate represented a distinct strain, with the exception of isolates

8 PHE11 and PHE12.

$9 \dagger \mathrm{\dagger}$ PCR can detect K1, K2, K5, K20, K54 and K57 capsular types.

$10 \$$ Corresponds to multi-locus sequence type ST14, often seen among multi-drug-resistant isolates

11 producing carbapenemases.

12 §Phage KLPN1 did not exhibit depolymerase activity on these K2 isolates, but it did on L4- 


\section{FAA5.}


Table 2 (on next page)

Table 2 - Characteristics of previously sequenced Klebsiella phages 
2 Table 2. Characteristics of previously sequenced Klebsiella phages

3

\begin{tabular}{|c|c|c|c|c|c|c|}
\hline Phage & Family & Size (bp) & $\mathrm{G}+\mathrm{C}(\%)$ & $\begin{array}{c}\text { No. of predicted } \\
\text { ORFs }\end{array}$ & $\begin{array}{c}\text { GenBank } \\
\text { accession no. }\end{array}$ & Reference \\
\hline NTUH-K2044-K1-1 & Podoviridae & 43,871 & 54.2 & 35 & NC_025418 & Lin et al. (2014a) \\
\hline F19 & Podoviridae & 43,766 & 53.8 & 51 & NC_023567 & - \\
\hline K11 & Podoviridae & 41,181 & 53.2 & 51 & NC_011043 & - \\
\hline KP34 & Podoviridae & 43,809 & 54.1 & 57 & NC_013649 & Drulis-Kawa et al. (2011) \\
\hline KP32 & Podoviridae & 41,119 & 52.4 & 44 & NC_013647 & Kęsik-Szeloch et al. (2013) \\
\hline P13 & Podoviridae & 45,976 & 51.7 & 50 & - & Shang et al. (2015) \\
\hline 0507-KN2-1 & Myoviridae & 159,991 & 46.7 & 154 & NC_022343 & Hsu et al. (2013) \\
\hline JD001 & Myoviridae & 48,814 & 48.5 & 68 & NC_020204 & Cui et al. (2012) \\
\hline KP27 & Myoviridae & 174,413 & 41.8 & 276 & NC_020080 & Kęsik-Szeloch et al. (2013) \\
\hline KP15 & Myoviridae & 174,436 & 41.8 & 258 & NC_014036 & Kęsik-Szeloch et al. (2013) \\
\hline vB_KleM-RaK2 & Myoviridae & 345,809 & 32 & 534 & NC_019526 & Šimoliūnas et al. (2012) \\
\hline K64-1 & Myoviridae & 346,602 & 31.72 & 64 & AB897757 & Pan et al. (2015) \\
\hline KP36 & Siphoviridae & 49,820 & 50.7 & 80 & NC_019781 & Kęsik-Szeloch et al. (2013) \\
\hline phiKO2 & Siphoviridae & 51,601 & 51.5 & 64 & NC_005857 & Casjens et al. (2004) \\
\hline 1513 & Siphoviridae & 49,462 & 50.61 & 72 & KP658157 & Cao et al. (2015) \\
\hline KLPN1 & Siphoviridae & 49,037 & 50.5 & 73 & KR262148 & This study \\
\hline
\end{tabular}

4

5

6 


\section{Table 3(on next page)}

Table 3 - Genomic structure of phage KLPN1 
Table 3. Genomic structure of phage KLPN1

3

\begin{tabular}{|c|c|c|c|c|c|c|c|c|c|c|}
\hline \multirow{2}{*}{$\begin{array}{l}\text { KLPN1 } \\
\text { genome }\end{array}$} & \multirow[t]{2}{*}{ Start } & \multirow[t]{2}{*}{ Stop } & \multirow{2}{*}{$\begin{array}{l}\text { Ribosome-binding } \\
\text { site }\end{array}$} & \multirow[t]{2}{*}{ Start } & \multirow[t]{2}{*}{ Strand } & \multirow{2}{*}{ Predicted product* } & \multicolumn{4}{|c|}{ Representative ORF in phage (\% amino acid identity) } \\
\hline & & & & & & & KP36 & F20 & 1513 & phiKO2 \\
\hline KLPN1_01 & 516 & 1079 & AAGGAG & ATG & + & Unknown & - & - & - & - \\
\hline KLPN1_02 & 1069 & 1290 & AGGAGG & ATG & + & HP & - & - & - & - \\
\hline KLPN1_03 & 1395 & 1547 & GAGGAA & ATG & + & HP pSf1_0028 (Shigella phage pSf-1) & - & - & $39(94)$ & - \\
\hline KLPN1_04 & 1752 & 1997 & GAAGAtAG & TTG & + & HP (Escherichia phage e4/1c) & - & - & $38(98.36)$ & - \\
\hline KLPN1_05 & 2186 & 2416 & AGGAGGA & ATG & + & HP KP36_04 KP36 & $04(74.65)$ & $76(63.38)$ & $37(92.11)$ & - \\
\hline KLPN1_06 & 2487 & 2699 & AGAGGA & ATG & + & HP KP36_06 KP36 & $06(82.86)$ & - & $36(90)$ & - \\
\hline KLPN1_07 & 2710 & 3030 & AAGGAGAA & ATG & + & HP KP36_11 KP36 & $11(78.3)$ & $70(65.09)$ & $35(82.08)$ & - \\
\hline KLPN1_08 & 3100 & 3471 & GGAGA & ATG & + & HP (Enterobacteria phage F20) & - & $69(83.74)$ & - & - \\
\hline KLPN1_09 & 3481 & 3783 & GAGGtGGccG & ATG & + & HP KP36_15 KP36 & $15(91)$ & $68(56)$ & $33(85)$ & - \\
\hline KLPN1_10 & 3783 & 4028 & AAcGGGA & ATG & + & HP KP36_16 KP36 & $16(97.53)$ & $67(83.95)$ & $32(92.59)$ & - \\
\hline KLPN1_11 & 4025 & 4210 & GAGGtAAAAG & ATG & + & HP KP36_17 KP36 (signal peptide) & $17(85.25)$ & $66(78.69)$ & $31(58.18)$ & - \\
\hline KLPN1_12 & 4291 & 4500 & AAtcAGGAG & ATG & + & HP (Enterobacteria phage F20) & - & $65(73.91)$ & - & - \\
\hline KLPN1_13 & 4500 & 4934 & GAGGAGA & ATG & + & HP (Enterobacteria phage F20) & $19(33.93)$ & $64(32.54)$ & $29(35.58)$ & - \\
\hline KLPN1_14 & 5004 & 5750 & AAGAGGAA & ATG & + & HP (Enterobacteria phage F20) & $20(50.94)$ & $63(54.55)$ & $28(34.84)$ & - \\
\hline KLPN1_15 & 5827 & 6099 & AGGAG & ATG & + & HP KP36_22 KP36 & $22(65.56)$ & $61(66.67)$ & - & - \\
\hline KLPN1_16 & 6096 & 6668 & AAGGtGAtcGAA & ATG & + & HP KP36_23 KP36 & $23(96.32)$ & $60(78.53)$ & $25(76.44)$ & - \\
\hline KLPN1_17 & 6738 & 6974 & AAGGAG & ATG & + & HP KP36_24 KP36 & $24(92.31)$ & $59 \mathrm{a}(86.3)$ & $24(96.15)$ & - \\
\hline KLPN1_18 & 6962 & 7195 & GGAGAAGG & ATG & + & HP KP36_25 KP36 & $25(100)$ & $59(87.01)$ & $23(95.45)$ & - \\
\hline KLPN1_19 & 7324 & 7518 & AAAGGG & ATG & + & HP KP36_26 KP36 & $26(96.67$ & $57(93.65)$ & $22(96.88)$ & - \\
\hline KLPN1_20 & 7512 & 7718 & AAGGGAA & ATG & + & HP KP36_27 KP36 (signal peptide) & $27(96.2)$ & $56(64.81)$ & $21(100)$ & - \\
\hline KLPN1_21 & 7773 & 8378 & GAAGcGGcGtAA & ATG & + & terminase small subunit KP36 & $28(92.53)$ & $55(91.95)$ & $20(90.8)$ & - \\
\hline KLPN1_22 & 8388 & 9992 & AAGGGccGA & ATG & + & terminase large subunit KP36 (terminase-like family: PF03237) & $29(99.25)$ & $54(98.13)$ & $19(99.44)$ & - \\
\hline KLPN1_23 & 10038 & 11348 & AAAcAAGGttGA & ATG & + & portal protein KP36 (phage portal protein, SPP1 Gp6-like: PF05133) & $30(98.62)$ & $53(91.78)$ & $18(99.31)$ & - \\
\hline KLPN1_24 & 11335 & 12102 & GGAGGcGGA & ATG & + & $\begin{array}{c}\text { capsid morphogenesis protein KP36 (phage head morphogenesis domain: } \\
\underline{\text { IPR } 006528)}\end{array}$ & $31(96.44)$ & $52(90.12)$ & $17(95.22)$ & - \\
\hline KLPN1_25 & 12104 & 12589 & GAGGttAG & ATG & + & $\begin{array}{l}\text { HP gp40 (Escherichia phage phiEB49) HNH endonuclease (HNH endonuclease: } \\
\qquad \underline{\text { PF13392) }}\end{array}$ & - & - & - & - \\
\hline KLPN1_26 & 12586 & 13716 & GGAGA & ATG & + & capsid protein KP36 & $32(99.47)$ & $51(93.09)$ & $16(99.47)$ & - \\
\hline KLPN1_27 & 13768 & 14286 & AGGAGA & ATG & + & HP KP36_33 KP36 & $33(96.2)$ & $50(50.87)$ & $15(96.84)$ & - \\
\hline KLPN1_28 & 14400 & 15359 & AGGAG & ATG & + & major capsid protein KP36_34 KP36 & $34(98.75)$ & $49(94.36)$ & $14(98.43)$ & - \\
\hline KLPN1_29 & 15451 & 15756 & GGAGcA & ATG & + & HP KP36_35 KP36 & $35(100)$ & $48(86.15)$ & $13(98.77)$ & - \\
\hline
\end{tabular}




\begin{tabular}{|c|c|c|c|c|c|c|c|c|c|c|}
\hline \multirow{2}{*}{$\begin{array}{l}\text { KLPN1 } \\
\text { genome }\end{array}$} & \multirow[t]{2}{*}{ Start } & \multirow[t]{2}{*}{ Stop } & \multirow{2}{*}{$\begin{array}{l}\text { Ribosome-binding } \\
\text { site }\end{array}$} & \multirow[t]{2}{*}{ Start } & \multirow[t]{2}{*}{ Strand } & \multirow[t]{2}{*}{ Predicted product* } & \multicolumn{4}{|c|}{ Representative ORF in phage (\% amino acid identity) } \\
\hline & & & & & & & KP36 & F20 & 1513 & phiKO2 \\
\hline KLPN1_30 & 15753 & 16226 & AAAAGcGcGGA & ATG & + & HP KP36_36 KP36 & $36(100)$ & $47(92.75)$ & $12(97.83)$ & - \\
\hline KLPN1_31 & 16232 & 16609 & GGtAGGtGA & ATG & + & HP KP36_37 KP36 & $37(99.2)$ & $46(94.4)$ & $11(98.4)$ & - \\
\hline KLPN1_32 & 16602 & 17039 & AGGGtGGcGA & ATG & + & HP KP36_38 KP36 & $38(100)$ & $45(92.41)$ & $10(99.05)$ & - \\
\hline KLPN1_33 & 17029 & 17463 & GAGcGAGG & ATG & + & HP (Enterobacteria phage F20) Tail protein (phage tail protein: PF13554) & $39(76.39)$ & $44(88.19)$ & $09(74.19)$ & - \\
\hline KLPN1_34 & 17450 & 18136 & GGAGGcGA & ATG & + & HP (Enterobacteria phage F20) Tail protein (phage tail protein: PF08813) & - & $\begin{array}{c}43 / 42 \\
(68.26 / 42.04)\end{array}$ & $08(43.36)$ & - \\
\hline KLPN1_35 & 18189 & 18845 & AGGAG & ATG & + & HP (Enterobacteria phage F20) Tail protein (phage tail protein: PF08813) & $40(91.67)$ & $42(82.87)$ & $08(96.33)$ & - \\
\hline KLPN1_36 & 18922 & 19248 & AGGAG & ATG & + & Tape measure chaperone protein (domain of unknown function DUF1789: PF08748) & $41(98.15)$ & $41(57.01)$ & $07(98.15)$ & - \\
\hline $\begin{array}{l}\text { KLPN1_36. } \\
1\end{array}$ & 19239 & 19562 & - & - & + & Tape measure chaperone protein $\frac{(\text { phage-related hypothetical protein DUF1799: }}{\text { PF08809) }}$ & - & $40(92.73)$ & $06(96.36)$ & - \\
\hline KLPN1_38 & 19620 & 22565 & GAtAAAGtAG & TTG & + & tail length tape-measure protein KP36 ( $\lambda$ phage tail tape-measure protein: PF09718) & $43(91.63)$ & $39(80.22 / 68.85)$ & $05(91.04)$ & - \\
\hline KLPN1_39 & 22568 & 22912 & AAcGAGGG & GTG & + & minor tail protein KP36 (minor tail protein: PF05939) & $44(88.6)$ & $38(87.72)$ & $04(86.84)$ & $16(28.32)$ \\
\hline KLPN1_40 & 22949 & 23734 & - & & + & minor tail protein KP36 (minor tail protein L: TIGR01600) & $45(93.17)$ & $37(91.27)$ & $03(92.77)$ & $17(36.78)$ \\
\hline KLPN1_41 & 23736 & 24473 & GAAAAGcGGAcGG & ATG & + & minor tail protein KP36 (endopeptidase, N1pC/P60 family: PF00877) & $46(93.47)$ & $36(96.33)$ & $02(94.69)$ & $18(42.62)$ \\
\hline KLPN1_42 & 24448 & 25050 & AAGGA & ATG & + & tail assembly protein $\mathrm{KP} 36(\lambda$ tail assembly protein I: PF06805) & 47 (94.5) & $35(98)$ & $01(95.03)$ & - \\
\hline KLPN1_43 & 25138 & 28839 & AGGAGG & ATG & + & tail fiber protein KP36 (putative phage tail protein: $\mathrm{PF} 13550$ ) & $48(95.86)$ & $34(88.6)$ & $\begin{array}{c}01 \mathrm{a} \\
(95.06)\end{array}$ & $21(39.75)$ \\
\hline KLPN1_44 & 29027 & 31297 & AAGAGG & ATG & - & $\begin{array}{l}\text { HP L418_01651 (Klebsiella pneumoniae UCICRE 7) (galactose-binding domain- } \\
\text { like: IPR008979) }\end{array}$ & $49(66.79)$ & $32(83.49)$ & $71(70.15)$ & - \\
\hline KLPN1_45 & 31392 & 31853 & AGGAAcGA & ATG & - & $\begin{array}{l}\text { single-stranded DNA binding protein KP36 (nucleic-acid binding proteins: } \\
\underline{\text { SSF50249) }}\end{array}$ & $50(98.04)$ & $31(82.35)$ & $70(96.08)$ & - \\
\hline KLPN1_46 & 31890 & 32546 & AAGGAAA & ATG & - & putative recombination protein KP36 (signal peptide) & $51(99.54)$ & $30(93.12)$ & $69(98.62)$ & - \\
\hline KLPN1_47 & 32606 & 33652 & GGAGcAA & ATG & - & exodeoxyribonuclease VIII KP36 (PD-(D/E)XK nuclease superfamily: PF12705) & $52(97.7)$ & $29(93.39)$ & $68(97.99)$ & - \\
\hline KLPN1_48 & 34148 & 35107 & GGAGGtAA & GTG & - & DNA primase KP36 (bacteriophage T7, Gp4, DNA primase/helicase, N-terminal: & $53(98.7)$ & $28(88.64)$ & $67(99.35)$ & - \\
\hline KLPN1_49 & 35183 & 35584 & GAGGGttAA & ATG & - & $\begin{array}{c}\text { putative transcriptional regulator KP36 } \underline{(\lambda \text { repressor-like, DNA-binding domain: }} \\
\qquad \underline{\text { IPR010982) }}\end{array}$ & $54(98.5)$ & $27(95.49)$ & $66(99.25)$ & - \\
\hline KLPN1_50 & 35676 & 37712 & AGGAttG & ATG & + & DNA helicase KP36 (helicase, C-terminal: IPR001650) & $55(98.52)$ & $26(94.25)$ & $65(98.82)$ & - \\
\hline KLPN1_51 & 37709 & 38116 & GGAGGcGAGG & GTG & + & HP KP36_56 KP36 (VRR-NUC domain: IPR014883) & $56(99.08)$ & $25(86.61)$ & $64(100)$ & - \\
\hline KLPN1_52 & 38181 & 38468 & GAAGAAcGGA & ATG & + & HP KP36_57 KP36 (signal peptide) & $57(95.65)$ & - & $63(94.87)$ & - \\
\hline KLPN1_53 & 38471 & 39202 & GcGAGGttAA & ATG & + & $\begin{array}{l}\text { DNA adenine methyltransferase KP36 (phage } N \text {-6-adenine-methyltransferase: } \\
\qquad \underline{\text { TIGR01712) }}\end{array}$ & $58(97.53)$ & $23(92.59)$ & $62(97.94)$ & - \\
\hline KLPN1_54 & 39204 & 39440 & GcGtAtGcGAA & ATG & + & HP KP36_59 KP36 & $59(88.46)$ & $22(79.49)$ & $61(89.74)$ & - \\
\hline KLPN1_55 & 39451 & 39741 & - & ATG & + & HP (Enterobacteria phage F20) & $60(98.72)$ & $21(83.33)$ & $60(98.72)$ & - \\
\hline KLPN1_56 & 39741 & 39989 & GGtGAcGA & ATG & + & HP KP36_61 KP36 & $61(95.18)$ & $20(89.02)$ & $59(96.39)$ & - \\
\hline
\end{tabular}




\begin{tabular}{|c|c|c|c|c|c|c|c|c|c|c|}
\hline \multirow{2}{*}{$\begin{array}{l}\text { KLPN1 } \\
\text { genome }\end{array}$} & \multirow{2}{*}{ Start } & \multirow[t]{2}{*}{ Stop } & \multirow{2}{*}{$\begin{array}{l}\text { Ribosome-binding } \\
\text { site }\end{array}$} & \multirow[t]{2}{*}{ Start } & \multirow[t]{2}{*}{ Strand } & \multirow[t]{2}{*}{ Predicted product* } & \multicolumn{4}{|c|}{ Representative ORF in phage (\% amino acid identity) } \\
\hline & & & & & & & KP36 & F20 & 1513 & phiKO2 \\
\hline KLPN1_57 & 40085 & 41215 & AAttGGGAtAA & ATG & + & HP KP36_62 KP36 (metallo-dependent phosphatase-like: IPR029052) & $62(99.2)$ & $19(94.15)$ & $58(99.2)$ & - \\
\hline KLPN1_58 & 41254 & 41745 & AAGGAAA & ATG & + & $\begin{array}{r}\text { 3'-phosphatase, 5'-polynucleotide kinase KP36 (HAD superfamily, subfamily IIIB } \\
\text { (acid phosphatase): PF03767) }\end{array}$ & $63(93.87)$ & $18(75.46)$ & $57(95.09)$ & - \\
\hline KLPN1_59 & 41742 & 42323 & GGAGtAGA & ATG & + & HP KP36_64 KP36 (P-loop containing nucleoside triphosphate hydrolase: & $64(99.48)$ & $17(88.17)$ & $56(99.48)$ & - \\
\hline KLPN1_60 & 42450 & 42665 & AGAGG & ATG & + & holin KP36 & $65(83.1)$ & $16(80.28)$ & $55(83.1)$ & - \\
\hline KLPN1_61 & 42667 & 43149 & AGGAGcAAG & ATG & + & endolysin KP36 (lysozyme-like domain: IPR023346) & $66(86.23)$ & $15(90.57)$ & $54(98.12)$ & - \\
\hline KLPN1_62 & 43146 & 43571 & AAGGA & ATG & + & Rz1A protein KP36 & $67(96.45)$ & $14(89.36)$ & $53(99.29)$ & - \\
\hline KLPN1_63 & 43641 & 44102 & GAGGtAA & ATG & - & HP KP36_68 KP36 & $68(98.69)$ & $13(88.89)$ & $52(98.69)$ & - \\
\hline KLPN1_64 & 44106 & 45674 & AGGAGcAAGG & ATG & - & HP KP36_69 KP36 (protein of unknown function DUF3987: PF13148) & $69(99.81)$ & $12(95.79)$ & $51(99.81)$ & - \\
\hline KLPN1_65 & 45800 & 46237 & GGAGAAAG & ATG & - & HP KP36_70 KP36 & $70(97.93)$ & $11(91.03)$ & $50(98.62)$ & - \\
\hline KLPN1_66 & 46238 & 46420 & GAAGAAA & ATG & - & HP KP36_71 KP36 & $71(93.33)$ & $10(86.44)$ & $49(93.33)$ & - \\
\hline KLPN1_67 & 46417 & 46620 & GGAGtAAAcGGA & ATG & - & HP KP36_72 KP36 & $72(97.01)$ & $09(65.67)$ & $48(92.54)$ & - \\
\hline KLPN1_68 & 46693 & 47385 & AAAtGGtGGA & ATG & - & HP KP36_73 KP36 & $73(97.83)$ & $08(90)$ & $47(96.96)$ & $42(56.83)$ \\
\hline KLPN1_69 & 47382 & 47681 & GGcAtAG & TTG & - & HP KP36_74 KP36 & $74(100)$ & $06(55.41)$ & $46(52.7)$ & - \\
\hline KLPN1_70 & 47688 & 48065 & GAAAcGAGG & ATG & - & HP KP36_75 KP36 & $75(96)$ & $05(66.13)$ & $45(70)$ & - \\
\hline KLPN1_71 & 48065 & 48304 & GAGAAGGG & ATG & - & HP KP36_76 KP36 & $76(96.2)$ & 04 (93.1) & 44 (97.47) & - \\
\hline KLPN1_72 & 48301 & 48495 & AGGAGAA & ATG & - & HP KP36_77 KP36 & 77 (93.75) & $03(84.81)$ & $43(95.31)$ & - \\
\hline KLPN1_73 & 48568 & 48849 & AGAGGG & ATG & - & HP KP36_78 KP36 & 78 (97.47) & $02(84.81)$ & $42(96.2)$ & - \\
\hline
\end{tabular}

4

5 *HP, hypothetical protein. Underlined predicted products are from InterProScan (http://www.ebi.ac.uk/interpro/) searches that

6 returned results with the amino acid sequence encoded by each ORF (Supplementary Table 2). 


\section{PeerJ Reviewing Manuscript}




\section{Table 4(on next page)}

Table 4 - Selected HHpred results for ORF34 and ORF35 of phage KLPN1 


\section{Table 4. Selected HHpred results for ORF34 and ORF35 of phage KLPN1}

3

\begin{tabular}{|c|c|c|c|c|c|c|c|c|}
\hline Hit & $\begin{array}{l}\text { Probability of } \\
\text { true positive }\end{array}$ & E-value & P-value & Score & SS & Cols & $\begin{array}{l}\text { ORF amino } \\
\text { acids }\end{array}$ & Reference \\
\hline \multicolumn{9}{|l|}{ ORF34 } \\
\hline $\begin{array}{l}\text { 2k4q_A Major tail protein V; GPV, bacteriophage lambda, viral protein; NMR } \\
\text { \{Enterobacteria phage lambda }\}\end{array}$ & 99.9 & $1.3 \times 10^{-27}$ & $3.6 \times 10^{-32}$ & 195.4 & 7.6 & 124 & $99-224$ & $\begin{array}{l}\text { Pell et al. } \\
\text { (2009) }\end{array}$ \\
\hline $\begin{array}{l}\text { 3ju4_A Endo- } N \text {-acetylneuraminidase; endonf, polysia, high-resolution, } \\
\text { glycosidase, hydrolase; HET: SLB; 0.98A \{Enterobacteria phage K1F\} }\end{array}$ & 81.6 & 1.4 & $4.1 \times 10^{-5}$ & 42.0 & 4.1 & 93 & $23-123$ & $\begin{array}{l}\text { Schulz et al. } \\
\quad(2010)\end{array}$ \\
\hline $\begin{array}{l}\text { 4hiz_A Endosialidase, PHI92_GP143; sialidase fold, beta-helix, endo-alpha2,8- } \\
\text { sialidase, endo-Al sialidase sialic acid polymer; HET: SLB SIA SUC; 1.60A } \\
\text { \{Enterobacteria phage PHI92\} }\end{array}$ & 80.9 & 4 & 0.00012 & 39.1 & 6.8 & 65 & $23-95$ & Unpublished \\
\hline \multicolumn{9}{|l|}{ ORF35 } \\
\hline $\begin{array}{l}\text { 2k4q_A Major tail protein V; GPV, bacteriophage lambda, viral protein; NMR } \\
\text { \{Enterobacteria phage lambda }\}\end{array}$ & 99.9 & $5.3 \times 10^{-28}$ & $1.5 \times 10^{-32}$ & 195.1 & 8.6 & 119 & $94-214$ & $\begin{array}{l}\text { Pell et al. } \\
\text { (2009) }\end{array}$ \\
\hline $\begin{array}{l}\text { 4hiz_A Endosialidase, PHI92_GP143; sialidase fold, beta-helix, endo-alpha2,8- } \\
\text { sialidase, endo-Al sialidase sialic acid polymer; HET: SLB SIA SUC; 1.60A } \\
\text { \{Enterobacteria phage PHI92\} }\end{array}$ & 91.4 & 0.55 & $1.6 \times 10^{-5}$ & 44.1 & 7.3 & 65 & $23-87$ & Unpublished \\
\hline $\begin{array}{l}\text { 3ju4_A Endo- } N \text {-acetylneuraminidase; endonf, polysia, high-resolution, } \\
\text { glycosidase, hydrolase; HET: SLB; 0.98A }\{\text { Enterobacteria phage K1F\} }\end{array}$ & 90.0 & 0.59 & $1.7 \times 10^{-5}$ & 43.8 & 6.2 & 65 & $23-87$ & $\begin{array}{l}\text { Schulz et al. } \\
\qquad(2010)\end{array}$ \\
\hline
\end{tabular}

4 
